\title{
A Mathematical Model to Study the Coupling Effect of Deformation-Seepage-Heat Transfer on Coalbed Methane Transport and Its Simulative Application
}

\author{
Jianlin Xie $\mathbb{B D}^{1,2}$ and Yangsheng Zhao $\mathbb{D}^{2}$ \\ ${ }^{1}$ School of Environment and Safety, Taiyuan University of Science and Technology, Taiyuan, Shanxi 030024, China \\ ${ }^{2}$ School of Mining Engineering, Taiyuan University of Technology, Taiyuan, Shanxi 030024, China \\ Correspondence should be addressed to Yangsheng Zhao; y-s-zhao@263.net
}

Received 26 February 2020; Revised 18 June 2020; Accepted 26 June 2020; Published 26 August 2020

Academic Editor: Mostafa S. Shadloo

Copyright (c) 2020 Jianlin Xie and Yangsheng Zhao. This is an open access article distributed under the Creative Commons Attribution License, which permits unrestricted use, distribution, and reproduction in any medium, provided the original work is properly cited.

\begin{abstract}
Injection of high-temperature water or steam into low-permeability coalbed for efficient and rapid extraction of coalbed methane has been studied by our university for many years and will soon be implemented in the field. With comprehensive consideration of coupling of heat transfer, water seepage, desorption of coalbed methane, and coal-rock mass deformation, the paper establishes a more comprehensive mathematical model of the coupling effect of deformation-seepage-heat transfer on coalbed methane transport. Compared with the previous studies, this theoretical model considers the change of adsorbed and free coalbed methane at high temperature and the coalbed methane transport caused by a high-temperature gradient. Using the Tunlan Coal Mine of Shanxi Coking Coal Group to conduct the numerical simulations on the coalbed methane extraction project using heat injection technology, results show that (1) high-temperature water flowed towards the extraction hole along fractured fissures, with seepage towards the coal mass on both sides of the fissure at the same time, gradually heating the coalbed and forming an arcuate distribution of temperature from high to low for an area from the fractured fissure to the coalbed upper and lower boundaries. On the thirtieth day of heat injection, the temperature of the coalbed in the heat injection area ranged from $140^{\circ} \mathrm{C}$ to $260^{\circ} \mathrm{C}$. (2) Under high temperatures, desorption of the coalbed gas was quick, and the adsorption gas content formed an oval funnel from the heat injection hole towards the extraction hole, centered by the fractured fissure, and migrating towards the coalbed upper and lower boundaries. Along with heat injection and extraction, the absorbed gas content rapidly decreased, and on the thirtieth day of injection, the absorbed gas content of the entire heat injection area decreased to $1.5 \mathrm{~m}^{3} / t$, only $7 \%$ of the original. (3) During heat injection, the coalbed gas pore pressure rapidly increased and reached $5.5 \mathrm{MPa}$ on the tenth day, about 4.5 times the original, and the pore pressure steadied at 3.5 MPa on the thirtieth day of extraction. Such a high gas pressure gradient promoted the rapid flow and drainage of the gas.
\end{abstract}

\section{Introduction}

Understanding the controls and influences on coalbed methane transportation is an important problem in production and safety technology related to safe and efficient coalbed methane and coal mining. Therefore, scholars continue to perform extensive studies from various angles. As the leader in coal production, China has also led in studies for extraction of coalbed methane and safety of coal mines. Zhao et al. [1] proposed a mathematical model of continuous media for solid and gas coupling coalbed methane transport focusing on coal and rock mass deformation. Zhao et al. [2] also included that coalbeds are typically fractured media composed of matrix blocks and fissures and took the modified effective stress law to reflect the adsorption swelling deformation of coalbed methane. They proposed a mathematical model of coalbed methane transport in fractured media, rather than continuous media, and performed numerical simulations on the emission of coalbed methane for drilling and extracting, 
along with on the coal face. Liu et al. [3] reviewed the international progress of studies on coalbed methane transport under multifield coupling effects in detail and provided many new study results. Wang et al. [4] proposed a deformation-seepage coupled model for the simulation of underground storage of carbon dioxide and improvement of coalbed methane extraction efficiency. This model considered permeability as a function of the effective stress, but the effects on permeability from the stress caused by adsorption were inconsistent. $\mathrm{Gu}$ and Chalaturnyk [5] established a new model of porosity and permeability. The model took fissures and matrix blocks as equivalent continuous elastic media and conducted permeability analysis on anisotropic coal seams and deemed that gas desorption/ adsorption might cause coal matrix shrinkage/expansion. This model also considered the effect of temperature variation and coal petrologic parameters. Zhang et al. [6] considered the action of free-phase and adsorbed-phase gas on the mechanical deformation of coal and determined that their coupling might change the pore volume. The change of coal adsorption might change the coal pores, and therefore they studied the effects of the coupling of gas flow and coal deformation. Chen et al. [7] extended the singlehole elastic model and included the flow and transport of gas mixtures (binary gases such as carbon dioxide and methane). Wu et al. [8,9] further extended the model to a two-hole elastic model (dual solid media-coal matrix and fissure), used for single gas and binary gas systems. Liu and Smirnov $[10,11]$ established a set of mathematical models regarding carbon dioxide storage, covering capillary pressure, relative permeability, porosity, coupling adsorption model, concentration, and temperature equation. The model focused on the important effects of matrix structure deformation and determined that the matrix might affect fluid flow and lead to a rapid decline in capillary pressure and relative permeability as well. Wei and Zhang [12] developed a simulation model of two-dimensional, two-phase, three-hole/dual permeability coupling fluid flow and geomechanical coalbed methane for the extraction of natural gas and water. The mobilization of mixed gas from thermal action could not be ignored, especially at high temperatures. Liang et al. and Sun et al. $[13,14]$ studied adsorption and desorption of coalbed methane under nonisothermal conditions and proposed mathematical models of solid-fluid coupling under nonisothermal conditions and finite element numerical methods. Xia et al. [15] studied the mathematical model of spontaneous heating in coal seams, and Zhu et al. [16] established a coupling model of coal deformation, coalbed methane transport, and heat transport and studied interactions of coal and gas under variable temperatures. Li et al. [17] studied a more comprehensive mathematical model of deformation-water vapor two-phase seepage/heat transfer. Recently, a number of scholars have also carried out some innovative works on the modeling of CBM extraction considering effective stress effect and sorption induced strain [18], coal matrix block deformation [19], sorption induced swelling modification of effective stress coefficient [20], and methane solubility in water-saturated coals [21].
All the work above is the continuous and in-depth development of studies on coalbed methane, undoubtedly playing a greater role in promoting the theory of coalbed methane extraction.

First, heat injection wells and gas extraction wells are drilled in the coal seam. Then, by injecting superheated steam into the heat injection well, the temperature of the coal body may rise rapidly due to the effect of heat conduction and convection heat transfer, which will promote the desorption of adsorbed gas. At the same time, from the heat injection well to the extraction well, the gas seepage pressure gradient will increase. Hence, the permeability of the coal seam is greatly improved, thereby greatly enhancing the efficiency of gas extraction. Studies on the extraction theory and technology of coalbed methane on heating have been rapidly promoted and implemented in China $[22,23]$. Zhao YS Team from Taiyuan University of Technology has conducted a large number of experiments with thermal-mechanical coupling of coalbed methane in recent years and have revealed the mechanisms of coalbed methane desorption, seepage, and volume expansion under high temperature, determined the effects of temperature on permeability, and found that transportation of coalbed methane over $100^{\circ} \mathrm{C}$ was vastly different from that at $30 \sim 50^{\circ} \mathrm{C}$. The effects of temperature are noticeable in gas adsorption/ desorption processes, seepage process, and the coupling process of gas and coal seams with temperature. This paper will elaborate on this problem from the mathematical model point of view and the extraction law of coalbed methane using heat injection technology in coal seams.

\section{Establishment of the Mathematical Model of Solid-Fluid-Heat Coupling Effect on Coalbed Methane Extraction Using Heat Injection Technology}

2.1. Basic Assumptions. Extraction of coalbed methane using heat injection not only involves the adsorption and desorption of coal and coalbed methane, heat convection, conduction and transmission, changes in the solid stress field, and several other processes but also involves changes in the permeability coefficient, adsorption constant, and other physical parameters related to the coal mass. To make the model better reflect these essential laws, the following basic assumptions are proposed:

(1) With the increase of temperature, some adsorbed coalbed methane is instantaneously desorbed and converted to free coalbed methane.

(2) The coalbed methane, water, and the solid matrix of coal mass can instantly reach local thermal equilibrium.

(3) The coalbed methane in coal seams is reserved in free and adsorbed states, in which coalbed methane in a free state can be regarded as an ideal gas, with the content of 


$$
q_{y l}=n \rho_{g}=n \frac{p_{g} M}{R T} .
$$

The content of the absorbed coalbed methane, along with the temperature variation law, is subordinated to the Langmuir adsorption equation:

$$
q_{x f}=\frac{a b p_{g}}{1+b p_{g}} \cdot \rho_{0} .
$$

According to the experimental results of [24], the adsorption coefficients $a$ and $b$ obey the exponential change law affected by temperature:

$$
\begin{aligned}
& a=a_{0} e^{-} \alpha_{T}^{T}, \\
& b=b_{0} e^{-\beta_{T} T} .
\end{aligned}
$$

The total content of the coalbed methane in the coal mass can be determined by

$$
C=q_{y l}+q_{x f}=n \frac{p_{g} M}{\mathrm{RT}}+\frac{a b p_{g}}{1+b p_{g}} \rho_{0} .
$$

(4) The volumetric strain caused by adsorbed coalbed methane of the coal mass conforms to the exponential law [23]:

$$
\varepsilon=\varepsilon_{0}\left(e^{\gamma C}-1\right) .
$$

(5) The seepage law of coalbed methane and water in coal seams conforms to the linear Darcy's law at the microsegment pressure gradient [23]:

$$
\Delta q_{i}=K_{i j} \Delta p_{, j}
$$

The entire interval conforms to the following formula [23]:

$$
q_{i}=K_{i j} p_{, j}
$$

$K_{i j}=K(\Theta, p)$; that is, the permeability coefficient $K$ is a function of stress and pore pressure [25]:

$$
k=k_{0} p^{-\eta} \exp \left[-b_{k}\left(\Theta-3 \alpha p_{g}\right)\right] .
$$

(6) The pressure of water and coalbed methane is always consistent throughout the entire seepage field; that is, the effect of surface tension is not considered at the gas-liquid interface, and the pressure of coalbed methane is the same as that of water; therefore,

$$
p_{g}=p_{w}
$$

(7) Pores and fissures within the coal mass are saturated by coalbed methane and water; therefore,

$$
S_{g}+S_{w}=1 \text {. }
$$

(8) The coal and rock mass in the elastic deformation stage obeys the generalized Hooke's law:

$$
\sigma_{i j}=\lambda \delta_{i j} e+2 \mu \varepsilon_{i j}
$$

(9) Under the action of coalbed methane, the effective stress state of the coal mass follows the modified Biot effective stress law [26]:

$$
\sigma_{i j}^{\prime}=\sigma_{i j}-\alpha p_{g} \delta_{i j} .
$$

The effective stress coefficient $a$ of Biot can be expressed as

$$
\alpha=\alpha_{1}-\alpha_{2} \Theta+\alpha_{3} p-\alpha_{4} \Theta p .
$$

(10) The volume deformation of coal and rock mass consists of two parts, the deformation of the solid matrix of coal and rock mass, and the deformation of pores and fissures:

$$
\alpha_{b}=(1-n) \alpha_{s}+n \alpha_{p} .
$$

It is assumed that $(1-n) \alpha_{s} \ll n \alpha_{p}$ and the volume deformation of the coal and rock mass is equal to that of the pores.

(11) The density of the water is no longer a constant but a function of pressure and temperature $\rho_{w}=\rho_{w}\left(p_{w}\right.$, $T_{w}$ ) and is expressed as follows [25]:

$$
\begin{aligned}
\frac{1}{\rho_{w}}= & 3.086-0.899017(4014.15-T)^{0.147166} \\
& -0.39(658.15-T)^{-1.6}(p-225.5)+\delta_{w} .
\end{aligned}
$$

2.2. Coalbed Methane Seepage Equation. Study on mass conservation of any representative elementary volume $(\mathrm{REV})$ can refer to the following equation:

$$
\operatorname{div}\left(\rho_{g} q_{g i}\right)=\frac{\partial C}{\partial t} .
$$

The component form is written as follows:

$$
\frac{\partial\left(\rho_{g} q_{g x}\right)}{\partial x}+\frac{\partial\left(\rho_{g} q_{g y}\right)}{\partial y}+\frac{\partial\left(\rho_{g} q_{g z}\right)}{\partial z}=\frac{\partial C}{\partial t} .
$$

Darcy's law (7) and coalbed methane content equation (4) can be substituted into formula (16), providing

$$
\begin{aligned}
\text { Left } & =\operatorname{div}\left(\rho q_{i}\right), \\
& =\frac{\partial}{\partial x_{i}}\left(\rho_{g} \frac{k_{x_{i}}}{\mu_{g}} \frac{\partial p_{g}}{\partial x_{i}}\right), \\
& =\sum_{1}^{3} \frac{\partial}{\partial x_{i}}\left(\frac{p M}{\operatorname{RT}} \frac{k_{x_{i}}}{\mu_{g}} \frac{\partial p_{g}}{\partial x_{i}}\right), \\
& =\sum_{1}^{3}\left(\frac{M}{2 \mathrm{RT}} \frac{\partial}{\partial x_{i}}\left(\frac{k_{x_{i}}}{\mu_{g}} \frac{\partial p_{g}^{2}}{\partial x_{i}}\right)+\frac{M}{2 \mathrm{RT}^{2}} \frac{k_{x_{i}}}{\mu_{g}} \frac{\partial p_{g}^{2}}{\partial x_{i}} \frac{\partial T}{\partial x_{i}}\right),
\end{aligned}
$$




$$
\begin{aligned}
\text { Right } & =\frac{\partial C}{\partial t}, \\
& =\frac{\partial}{\partial t}\left(q_{y l}+q_{x f}\right), \\
& =\frac{\partial}{\partial t}\left(n S_{g} \frac{p_{g} M}{\mathrm{RT}}+\frac{a b p_{g}}{1+b p_{g}} \rho_{0}\right),
\end{aligned}
$$

including

$$
\begin{aligned}
& \sum_{1}^{3}\left(\frac{M}{2 \mathrm{RT}} \frac{\partial}{\partial x_{i}}\left(\frac{k_{x_{i}}}{\mu} \frac{\partial p_{g}^{2}}{\partial x_{i}}\right)+\frac{M}{2 \mathrm{RT}^{2}} \frac{k_{x_{i}}}{\mu} \frac{\partial p_{g}^{2}}{\partial x_{i}} \frac{\partial T}{\partial x_{i}}\right), \\
& \quad=\frac{S_{g} M p_{g}}{\mathrm{RT}} \frac{\partial n}{\partial t}+\frac{S_{g} n M}{\mathrm{RT}} \frac{\partial p_{g}}{\partial t}-\frac{S_{g} M \cdot n \cdot p_{g}}{\mathrm{RT}^{2}} \frac{\partial T}{\partial t}+\frac{n p_{g} M}{\mathrm{RT}} \frac{\partial S_{g}}{\partial T}+\frac{\rho_{0} b p_{g}}{1+b p_{g}} \frac{\partial a}{\partial t}+\frac{\rho_{0} a p_{g}}{\left(1+b p_{g}\right)^{2}} \frac{\partial b}{\partial t}+\frac{\rho_{0} a b}{\left(1+b p_{g}\right)^{2}} \frac{\partial p_{g}}{\partial t}, \\
& \quad=\frac{S_{g} M p_{g}}{\mathrm{RT}} \frac{\partial n}{\partial t}+\frac{n p_{g} M}{\mathrm{RT}} \frac{\partial S_{g}}{\partial T}+\left(\frac{S_{g} n M}{\mathrm{RT}}+\frac{\rho_{0} a b}{\left(1+b p_{g}\right)^{2}}\right) \frac{\partial p_{g}}{\partial t}-\frac{S_{g} M \cdot n \cdot p_{g}}{\mathrm{RT}^{2}} \frac{\partial T}{\partial t}+\frac{\rho_{0} b p_{g}}{1+b p_{g}} \frac{\partial a}{\partial t}+\frac{\rho_{0} a p_{g}}{\left(1+b p_{g}\right)^{2}} \frac{\partial b}{\partial t} .
\end{aligned}
$$

$$
\begin{aligned}
& \frac{\partial a}{\partial t}=\frac{\partial a}{\partial T} \frac{\partial T}{\partial t}=a_{0} \alpha_{T} e^{-\alpha_{T} T} \frac{\partial T}{\partial t}, \\
& \frac{\partial b}{\partial t}=\frac{\partial b}{\partial T} \frac{\partial T}{\partial t}=b_{0} \beta_{T} e^{-\beta_{T} T} \frac{\partial T}{\partial t} .
\end{aligned}
$$

The following can be obtained with the integration of formulas (16) (21):
These equations are the general transport and seepage equations of coalbed methane considering solid deformation, temperature action, adsorption parameter variations, and several other factors.

The following formulas can be obtained from partial derivative of time from formula (3): $\partial a / \partial t$ and $\partial b / \partial t$ in formula (23) can then be substituted into formula (22):

$$
\begin{aligned}
& \sum_{1}^{3}\left(\frac{M}{2 \mathrm{RT}} \frac{\partial}{\partial x_{i}}\left(\frac{k_{x_{i}}}{\mu} \frac{\partial p_{g}^{2}}{\partial x_{i}}\right)+\frac{M}{2 \mathrm{RT}^{2}} \frac{k_{x_{i}}}{\mu} \frac{\partial p_{g}^{2}}{\partial x_{i}} \frac{\partial T}{\partial x_{i}}\right) \\
& \quad=\frac{S_{g} M p_{g}}{\mathrm{RT}} \frac{\partial n}{\partial t}+\frac{n p_{g} M}{\mathrm{RT}} \frac{\partial S_{g}}{\partial T}+\left(\frac{S_{g} n M}{\mathrm{RT}}+\frac{\rho_{0} a_{0} b_{0} \alpha \beta e^{-(\alpha+\beta) T}}{\left(1+b p_{g}\right)^{2}}\right) \frac{\partial p_{g}}{\partial t} \\
& \quad+\left(\frac{\rho_{0} a_{0} b_{0} \alpha \beta e^{-(\alpha+\beta) T} p_{g}}{1+b_{0} e^{-\beta T} p_{g}}+\frac{\rho_{0} a_{0} b_{0} \alpha \beta e^{-(\alpha+\beta) T} p_{g}}{\left(1+b_{0} e^{-\beta T} p_{g}\right)^{2}}-\frac{S_{g} M \cdot n \cdot p_{g}}{\mathrm{RT}^{2}}\right) \frac{\partial T}{\partial t} .
\end{aligned}
$$

Equation (24) is the coalbed methane seepage equation considering deformation, saturation, seepage pressure, temperature action, and several other factors.
2.3. Water Seepage Control Equation. The mass conservation of water in any representative elementary volume can be expressed by the following formula: 


$$
\operatorname{div}\left(\rho_{w} q_{w}\right)=\frac{\partial\left(n \rho_{w}\right)}{\partial t}-W_{l} .
$$

With respect to the saturation of coalbed methane and water in the pores, then

$$
\begin{aligned}
\operatorname{div}\left(\rho_{w} q_{w}\right) & =\frac{\partial\left(n S_{w} \rho_{w}\right)}{\partial t}-W_{l} \\
& =S_{w} \rho_{w} \frac{\partial n}{\partial t}+n \rho_{w} \frac{\partial S_{w}}{\partial t}+n S_{w} \frac{\partial \rho_{w}}{\partial t}-W_{l} .
\end{aligned}
$$

According to assumption (11), water density is a function of temperature and water pressure; therefore,

$$
\frac{\partial \rho_{w}}{\partial t}=\frac{\partial \rho_{w}}{\partial T} \frac{\partial T}{\partial t}+\frac{\partial \rho_{w}}{\partial p_{w}} \frac{\partial p_{w}}{\partial t}
$$

Assumption (5) regarding Darcy's law for water seepage can then be substituted into formula (25), providing

$$
\begin{gathered}
\frac{\partial}{\partial x}\left(\frac{k_{x}}{\mu_{w}} \frac{\partial p_{w}}{\partial x}\right)+\frac{\partial}{\partial y}\left(\frac{k_{y}}{\mu_{w}} \frac{\partial p_{w}}{\partial y}\right)+\frac{\partial}{\partial z}\left(\frac{k_{z}}{\mu_{w}} \frac{\partial p_{w}}{\partial z}\right) \\
=S_{w} \rho_{w} \frac{\partial n}{\partial t}+n \rho_{w} \frac{\partial S_{w}}{\partial t}+n S_{w} \frac{\partial \rho_{w}}{\partial t}-W_{l} .
\end{gathered}
$$

This formula is the water seepage equation considering the deformation of coal and rock mass. As seen from the right side of the equation, the distribution of seepage pressure is affected by the solid matrix deformation, saturation, fluid pressure changing with time, and several other factors.

\subsection{Temperature Field Control Equation considering Gas-} Water Convective Heat Transfer and Heat Conduction of Coal and Rock Mass. During the heat injection and extraction of coalbed methane, the fluid undergoes heat transfer by convection, and the coal and rock mass matrix undergoes heat transfer by heat conduction, with different heat transfer characteristics between the two materials, so the heat transfer equations need to be established, respectively, for analysis.

Heat conduction equation of a solid matrix is as follows:

$$
(1-n) \rho_{s} c_{s} \frac{\partial T}{\partial t}=(1-n) \lambda_{s} \nabla T_{s}^{2}+Q_{0} .
$$

Fluid convective heat transfer equation is as follows:

$$
\begin{aligned}
n \frac{\partial T}{\partial t} & +\left(u \frac{\partial T}{\partial x}+v \frac{\partial T}{\partial y}+w \frac{\partial T}{\partial z}\right) \\
& =n \frac{\lambda_{w}}{\rho c_{p}}\left(\frac{\partial^{2} T}{\partial x^{2}}+\frac{\partial^{2} T}{\partial y^{2}}+\frac{\partial^{2} T}{\partial z^{2}}\right)+Q_{1} .
\end{aligned}
$$

Formulas for specific heat, heat conductivity, and density of the mixed fluid are shown as follows:

$$
\begin{gathered}
c_{p}=S_{g} c_{g}+S_{w} c_{w}, \\
\lambda_{z}=S_{g} \lambda_{g}+S_{w} \lambda_{w}, \\
\rho=S_{g} \rho_{g}+S_{w} \rho_{w} .
\end{gathered}
$$

Combined with assumption (6), formula (31) can be substituted into formula (30):

$$
\begin{aligned}
& n\left(S_{g} \rho_{g}+S_{w} \rho_{w}\right)\left(S_{g} c_{g}+S_{w} c_{w}\right) \frac{\partial T}{\partial t} \\
& \quad+\frac{\left(S_{g} \rho_{g}+S_{w} \rho_{w}\right)\left(S_{g} c_{g}+S_{w} c_{w}\right)}{S_{g} \mu_{g}+S_{w} \mu_{w}} k_{i} \nabla p_{w} \cdot \nabla T \\
& \quad=n\left(S_{g} \lambda_{g}+S_{w} \lambda_{w}\right) \nabla T^{2}+Q_{1} .
\end{aligned}
$$

According to assumption (2), coal, rock mass, and fluids are always in a state of thermal equilibrium, and formulas (29) and (32) can be superposed:

$$
\begin{aligned}
& (\rho c)_{t} \frac{\partial T}{\partial t}+\frac{\left(S_{g} \rho_{g}+S_{w} \rho_{w}\right)\left(S_{g} c_{g}+S_{w} c_{w}\right)}{S_{g} \mu_{g}+S_{w} \mu_{w}} k_{i} \nabla p_{w} \cdot \nabla T \\
& =\lambda_{z} \nabla T^{2}+Q .
\end{aligned}
$$

In the formulas above, $(\rho c)_{t}$ is defined as the equivalent heat capacity coefficient of two-phase fluid in coal and rock mass.

2.5. Coal and Rock Mass Deformation Equation. According to the elasticity theory, the static equilibrium equation of coal and rock mass is

$$
\sigma_{i j, j}+F_{i}=0 .
$$

According to assumptions (8) and (9), in view of the pore pressure action of coalbed methane, deformation caused by coalbed methane desorption, and the deformation of coal seams caused by temperature variation, the stress equilibrium equation expressed by displacement is

$$
\begin{aligned}
(\lambda & +\mu) u_{j, j i}+\mu u_{i, j j}+\left(\alpha \delta_{i j} p\right)_{, i}+\left(\omega_{c} \delta_{i j} C\right)_{, i} \\
& +\left(\alpha_{s} \delta_{i j} T\right)_{, i}+F_{i}=0 .
\end{aligned}
$$

Equation (34) is the equation of deformational movement of coal and rock mass expressed by displacement, with the consideration of pore pressure, temperature, and adsorption and desorption of coalbed methane.

\subsection{Mathematical Model of Heat-Fluid-Solid Coupling Effect on Coalbed Methane Extraction Using Heat Injection Technology. Combined with the coalbed methane seepage equation considering the temperature action, the water seepage equation considering rock deformation, the tem- perature field control equation considering gas-water con- vective heat transfer and heat conduction of coal and rock mass, and related coupling equations, the solid-fluid-heat coupling control equation for coalbed methane extraction using heat injection technology can then be established and expressed as}




$$
\begin{aligned}
& \sum_{1}^{3}\left(\frac{M}{2 \mathrm{RT}} \frac{\partial}{\partial x_{i}}\left(\frac{k_{x_{i}}}{\mu} \frac{\partial p_{g}^{2}}{\partial x_{i}}\right)+\frac{M}{2 \mathrm{RT}^{2}} \frac{k_{x_{i}}}{\mu} \frac{\partial p_{g}^{2}}{\partial x_{i}} \frac{\partial T}{\partial x_{i}}\right) \\
& \downarrow \\
& \text { I } \\
& =\frac{S_{g} M p_{g}}{\mathrm{RT}} \frac{\partial n}{\partial t}+\frac{n p_{g} M}{\mathrm{RT}} \frac{\partial S_{g}}{\partial T}+\left(\frac{S_{g} n M}{\mathrm{RT}}+\frac{\rho_{0} a b}{\left(1+b p_{g}\right)^{2}}\right) \frac{\partial p_{g}}{\partial t}-\frac{S_{g} M \cdot n \cdot p_{g}}{\mathrm{RT}^{2}} \frac{\partial T}{\partial t}+\frac{\rho_{0} b p_{g}}{1+b p_{g}} \frac{\partial a}{\partial t}+\frac{\rho_{0} a p_{g}}{\left(1+b p_{g}\right)^{2}} \frac{\partial b}{\partial t} \\
& \downarrow \quad \downarrow \quad \downarrow \quad \downarrow \quad \downarrow \quad \downarrow \\
& \begin{array}{llllll}
\text { II } & \text { III } & \text { IV } & \text { V } & \text { VI } & \text { VII }
\end{array} \\
& \frac{\partial}{\partial x}\left(\frac{k_{x}}{\mu_{w}} \frac{\partial p_{w}}{\partial x}\right)+\frac{\partial}{\partial y}\left(\frac{k_{y}}{\mu_{w}} \frac{\partial p_{w}}{\partial y}\right)+\frac{\partial}{\partial z}\left(\frac{k_{z}}{\mu_{w}} \frac{\partial p_{w}}{\partial z}\right)=S_{w} \rho_{w} \frac{\partial n}{\partial t}+n \rho_{w} \frac{\partial S_{w}}{\partial t}+n S_{w} \frac{\partial \rho_{w}}{\partial t}-W_{l} \\
& \text { IX } \\
& (\rho c)_{t} \frac{\partial T}{\partial t}+\frac{\left(S_{g} \rho_{g}+S_{w} \rho_{w}\right)\left(S_{g} c_{g}+S_{w} c_{w}\right)}{S_{g} \mu_{g}+S_{w} \mu_{w}} k_{i} \nabla p_{w} \cdot \nabla T=\lambda_{z} \nabla T^{2}+Q \\
& (\lambda+\mu) u_{j, j i}+\mu u_{i, j j}+\left(\alpha \delta_{i j} p\right)_{, i}+\left(\omega_{c} \delta_{i j} C\right)_{, i}+\left(\alpha_{s} \delta_{i j} T\right)_{, i}+F_{i}=0, \\
& \downarrow \quad \downarrow \quad \downarrow \\
& \text { X XI XII } \\
& S_{g}+S_{w}=1, \\
& p_{w}=p_{g} .
\end{aligned}
$$

The above equations, containing eight unknowns and eight variables and supplemented by initial and boundary value conditions, form the complete mathematical model of coalbed methane extraction using heat injection technology. The model is extremely nonlinear and unable to obtain its analytical solutions directly but can have approximate solutions determined by numerical methods.

\section{Mathematical Model Analysis and Discussion}

Liang et al. [13] considered that coal temperature might be reduced by $5^{\circ} \mathrm{C}$ or so during gas drainage in "the mathematical model and numerical solution of gas flow under unequal temperature," which cannot be ignored during the gas seepage process. The model reflected the effect of temperature on the gas seepage process, with certain advanced nature. Zhao [23] established a model of coal gas interaction under variable temperatures, took the coal gas content under high temperature as an important action term of the seepage equation, and conducted detailed reasoning on the evolution of the coal matrix pores affected by temperature and solid deformation. They then proposed a mathematical model of solid-fluid-heat coupling effect on gas flow and carried out numerical simulation of coal gas interaction under variable temperatures, while he did not consider the action on gas seepage from the diffusion terms of temperature field; i.e., the term $\partial T / \partial x_{i}$ which was not included in equation (19) only considered the effect of temperature on adsorption/desorption terms within their study on gas transport in fissures and coal matrix in the selfheating of coal seams. 
The mathematical model of heat-fluid-solid coupling effect considering effect of temperature on coalbed methane seepage, gas-water coexistence, and many other factors in the paper, compared with the existing mathematical models $[27,28]$, mainly has the main characteristics as follows:

(1) Term I, $\left(M / 2 \mathrm{RT}^{2}\right)\left(k_{x_{i}} / \mu\right)\left(\partial p_{g}^{2} / \partial x_{i}\right)\left(\partial T / \partial x_{i}\right)$, at the left end of the equation, refers to the gas migration term caused by temperature gradient, with a large effect on transport of coalbed methane under large temperature gradient, which cannot be ignored, and this term is not considered in existing models.

(2) Terms II and III at the right end of the equation, respectively, consider the actions of solid deformation and gas-water relative saturation.

(3) Terms IV and V at the right end of the equation refer to the effect of pore pressure variation of free and absorbed coalbed methane on the seepage process, respectively.

(4) Term VI at the right end of the equation refers to the effect of temperature variation on free coalbed methane transport, while terms VII and VIII refer to the effect of temperature on adsorbed-phase coalbed methane, further affecting the mechanisms of seepage process:

$$
\begin{aligned}
& \frac{\partial a}{\partial t}=\frac{\partial a}{\partial T} \frac{\partial T}{\partial t}=a_{0} \alpha e^{-\alpha T} \frac{\partial T}{\partial t} \\
& \frac{\partial b}{\partial t}=\frac{\partial b}{\partial T} \frac{\partial T}{\partial t}=b_{0} \beta e^{-\beta T} \frac{\partial T}{\partial t}
\end{aligned}
$$

(5) Terms X and XI in the solid deformation equation of the model refer to the action of pore pressure on solid deformation and the action of adsorbed-phase coalbed methane on solid deformation, respectively.

From the analysis of the mathematical model of the solid-fluid-heat coupling effect on coalbed methane transport proposed in the paper, the distinctive characteristics and developments mentioned above are not included in existing mathematical models, which is another important progress in the theoretical model of coalbed methane transport.

The main idea of program design is to perform time loops on various physics fields (see Figure 1). In each time loop, each physics field is analyzed separately, and then the relevant parameters are coupled and iterated to solve. The specific design process is as follows: (1) According to the existing initial and boundary conditions, we first calculate the temperature field distribution of the coal and rock mass at time $t_{0}$, so as to obtain the relative saturation of two-phase gas-liquid fluid. At the same time, according to the temperature value at this time, the physical parameters of fluid and coal matrix are reassigned, and the above parameters are substituted into the seepage equation. (2) The pressure and velocity of the fluid are calculated based on the seepage equation, and then the calculated values are substituted into the seepage equation of coalbed methane. (3) Calculate the pore pressure of each node on coal seam, and obtain the gas content of each unit. Correspondingly, the expansion stress of coal and rock mass caused by adsorption can be obtained. (4) Calculate the stress field distribution of coal mass under the coupled process of coalbed methane adsorption, geostatic stress, pore pressure, thermal stress, and expansion stress. (4) When $t_{1}=t_{0}+\Delta t$, repeat the above steps (1)-(3). In this way, the distribution and variational trend of various physical parameters with multiphysics coupling process during in situ heat injection mining process of coalbed methane can be obtained. The flowchart of the calculation program according to the above method is shown in Figure 1.

\section{Numerical Simulation Test of Coalbed Methane Extraction in Coal Seams Using Heat Injection Technology}

\subsection{Calculation Model Simplification}

4.1.1. Mining Area Survey. The mining area, Tunlan Coal Mine, is a modern superhuge coal mine operated by the Xishan Coal Electricity Group Co., Ltd. of the Shanxi Coking Coal Group, with an annual production capacity of 5 million tons. The mining area is $6 \mathrm{~km}$ south of Gujiao City, Shanxi Province, with a minefield area of $73.33 \mathrm{~m}^{2}$, industrial reserves of 1,028 million tons, and recoverable reserves of 628 million tons. Main coal types in production include coking coal, fat coal, and a small amount of lean coal. The minefield contains 13 layers of coal in total, and the total thickness of the coal-bearing strata is $161.59 \mathrm{~m}$, while the actual total thickness of the coal seams is $17.64 \mathrm{~m}$, with a coal-bearing coefficient of $10.92 \%$. There are six minable seams, No.2, No. 3, No. 6, No. 7, No. 8, and No. 9, with a total minable seam of $15.08 \mathrm{~m}$ and a mineable coal-beating coefficient of $9.33 \%$. The thickness of the $2 \#$ coal seam used here as an example is $6^{\circ} \mathrm{m}$. In the crossheading of the working face, the horizontal drilling was taken with an interval of $100 \mathrm{~m}$, to form drilling holes for heat injection and production.

4.1.2. Model Simplification. Hexahedron isoparametric elements were used to divide the area into 2,448 nodes and 1,650 units.

According to the mathematical model of the "solid-fluidheat" coupling effect on coalbed methane extraction using heat injection technology proposed in formula (35) and the parameters of the test area, it was assumed that the physical and mechanical characteristics of the coal mass in each section were consistent along the drainage aperture, and the section perpendicular to the drill holes was used as the calculation model, which is $100^{\circ} \mathrm{m}$ in length, $0.3 \mathrm{~m}$ in width, and $6^{\circ} \mathrm{m}$ in height. The simplified geometrical-physical model can be seen in Figures 2 and 3. Initial and boundary conditions can be seen in Table 1. Basic physical and mechanical parameters of the test model can be seen in Table 2.

4.2. Numerical Test. This paper establishes a numerical model based on the $2 \#$ coal seam of Tunlan Coal Mine, with the heat injection hole set on the left of the model and the drainage hole set on the right, and conducts numerical simulation calculation with the consideration of "solid-fluid-heat" coupling. 


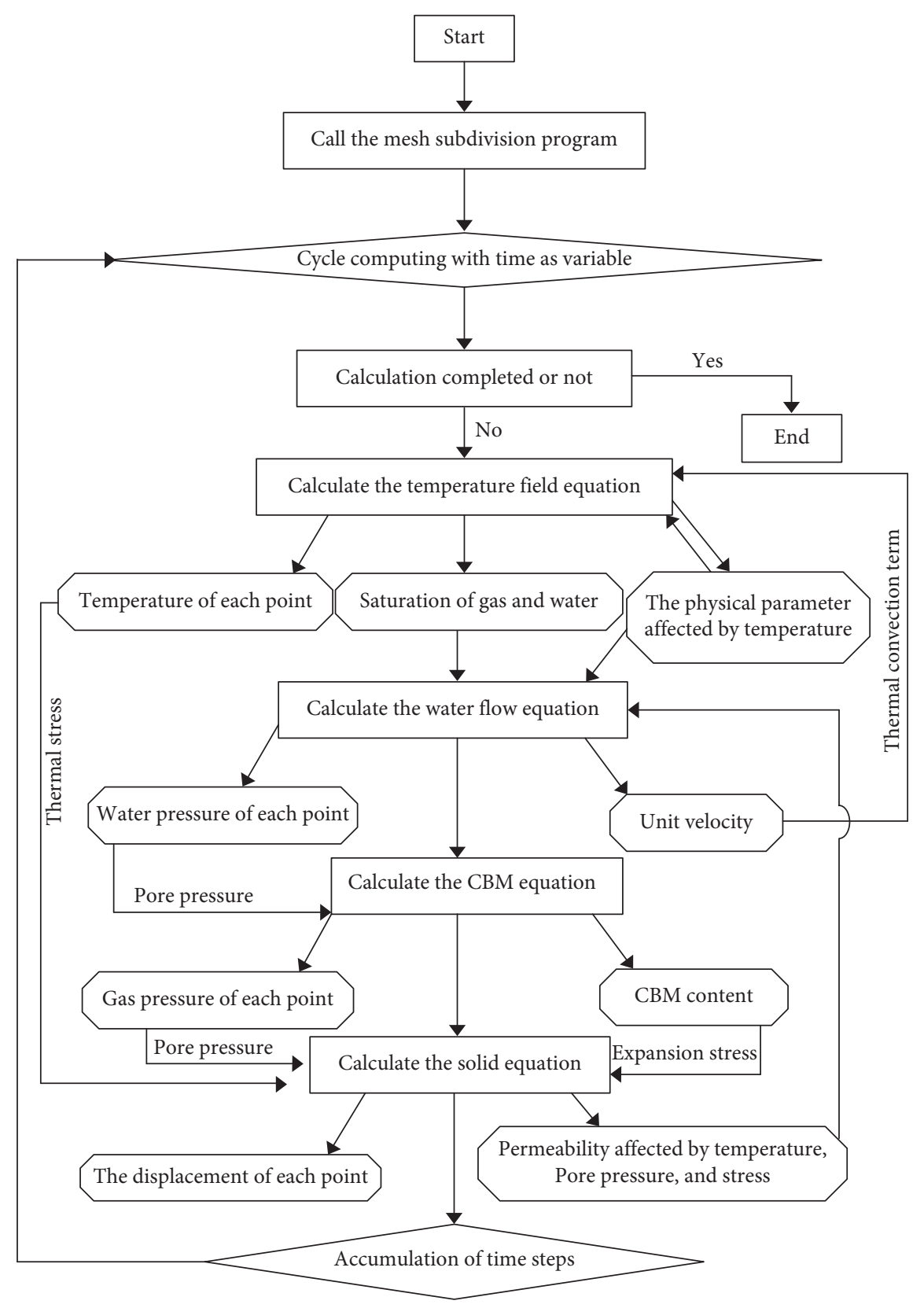

FIgURE 1: The block diagram of program design in this study.

This model took time as the loop variable and calculated numerical solutions of the heat transfer equation, coalbed methane seepage equation, solid deformation equation, and other coupling equations at different times, respectively. According to the calculation results, the temperature field variations of the coal mass and the variations of coalbed methane content in coal seams during heat injection of coal seams are analyzed, respectively. The results are potted for 3 days, 10 days, 20 days, and 30 days in Figures 4-13. Injection. Figure 4(a) shows that the state of heat transfer in coal seams was clear after heat injection for 3 days; that is, under the condition of hydraulic fracturing and convective heat transfer, coal mass and high-temperature water reached thermal equilibrium very quickly, and temperature rose rapidly in the water injection areas. The temperature of the coal seams in the area of the heat injection holes reached $250^{\circ} \mathrm{C}$, with the fissure zone as the boundary, and the temperature of the upper and lower coal seams gradually rose. The temperature rises in Figures 4(b)-4(d) gradually expanded from the fissure zone towards the bottom and top beds. After 10 days of heat injection, the temperature of top and bottom beds rose to $50^{\circ} \mathrm{C}$, and the temperature of the fissure zone reached $260^{\circ} \mathrm{C}$; after heat injection for 20 days, the 


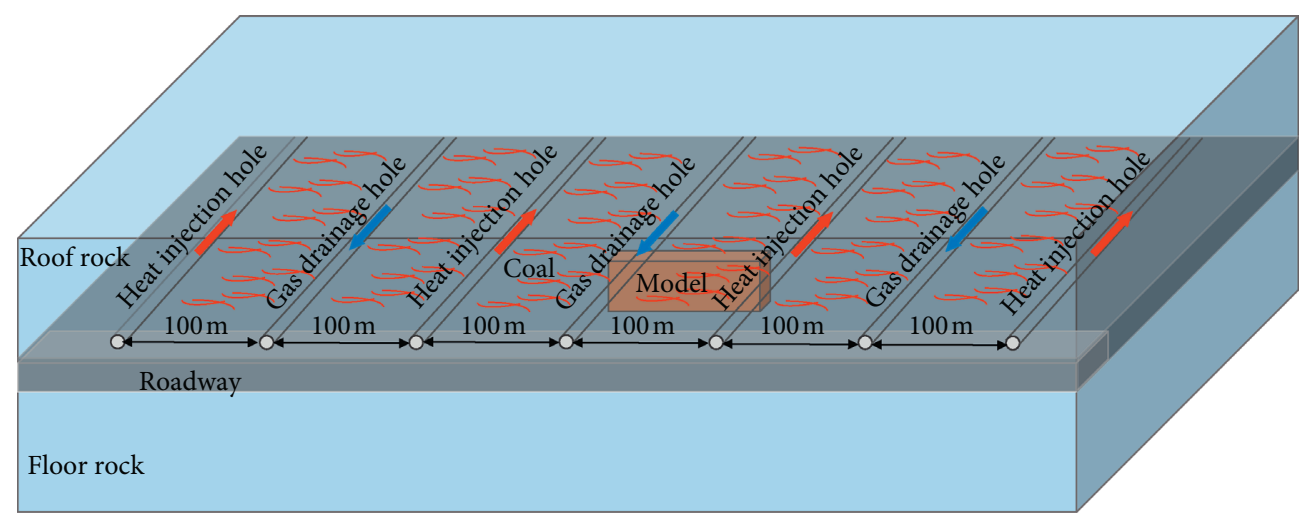

FIgURE 2: The schematic diagram of gas extraction by heat injection.

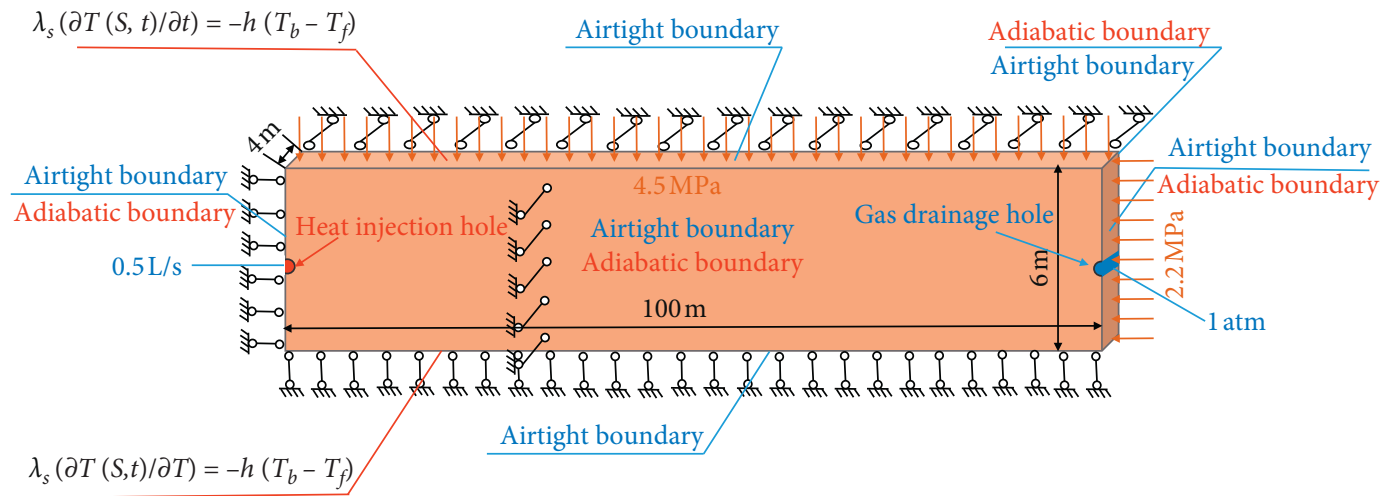

Figure 3: Mechanical model of the XZ plane.

TABLE 1: Initial and boundary conditions.

\begin{tabular}{|c|c|c|}
\hline Equation category & Initial conditions & Boundary conditions \\
\hline Gas seepage equation & $p_{g}(x, y, z, t)_{t=t_{0}}=13.25 \mathrm{~atm}$ & $\begin{array}{l}\text { All sides of the model are airtight boundaries (except the extraction } \\
\text { hole): } \partial p_{g} / \partial n=0 \\
\text { Extraction hole: } p_{g}\left(x_{1}, y_{1}, z_{1}, t\right)=1 \text { atm }\end{array}$ \\
\hline $\begin{array}{l}\text { Temperature field } \\
\text { control equation }\end{array}$ & $\begin{array}{l}\text { Initial temperature of primitive coalbed: } \\
\qquad T(x, y, z, t)_{t=t_{0}}=25^{\circ} \mathrm{C}\end{array}$ & $\begin{array}{l}\text { Front, rear, left, and right boundaries: adiabatic boundaries, } \\
\qquad-\lambda_{s}(\partial T / \partial n)_{w}=0 \\
\text { Upper and lower boundary conditions: } \lambda_{s}(\partial T(S, t)) / \partial t=-h\left(T_{b}-T_{f}\right) \\
\text { In the formula, } T_{b} \text { refers To model boundary temperature, } T_{f} \text { refers to } \\
\text { the temperature of the model from the boundary } \delta_{b} \text { to the inside, and } \lambda_{r} \\
\text { refers to the coefficient of thermal conductivity of the upper and lower } \\
\text { rock mass in coal seams, } h=\lambda_{r} / \delta_{b}\end{array}$ \\
\hline Solid stress equation & & $\begin{array}{l}\text { Displacement boundaries: lower boundary, } w=0 \text {; left boundary, } u=0 \text {; } \\
\text { front and rear boundaries, } v=0 \\
\text { Stress boundaries on the top and right side: uniform load boundaries, } \\
\sigma_{1}=4.5 \mathrm{MPa} \text { and } \sigma_{2}=2.2 \mathrm{MPa}\end{array}$ \\
\hline $\begin{array}{l}\text { Fluid seepage field } \\
\text { equation }\end{array}$ & $p_{w}(x, y, z, t)_{t=0}=0$ & Water injection well: $q_{w}\left(x_{0}, y_{0}, z_{0}, t\right)=0.5 \mathrm{~L} / \mathrm{s}$ \\
\hline
\end{tabular}

temperature of the top and bottom beds most distant from the fissure zone rose to $92^{\circ} \mathrm{C}$, and the temperature of the top and bottom beds of coal seams rose to $126^{\circ} \mathrm{C} 30$ days later.

Figure 5 is the temperature field distribution profile of the model on the $y=0$ plane. After 30 days, the temperature reached almost $280^{\circ} \mathrm{C}$ within $2 \mathrm{~m}$ of the fissure zone up and down. Later, it gradually expanded from the fissure zone to the bottom and top beds, and the temperature accelerated desorption of coalbed methane in the coal mass.

4.2.2. Variation Law of Adsorbed Gas Content. Figures 6 and 7 are variation diagrams of adsorbed coalbed methane along with heat injection and extraction. 
TABLE 2: Modeling parameters for the numerical simulation.

\begin{tabular}{|c|c|c|}
\hline Parameter name & Numerical value & Unit \\
\hline Young's modulus of coal seams, $E$ & 2183.1 & $\mathrm{MPa}$ \\
\hline Poisson's ratio of coal seams, $V$ & 0.3274 & - \\
\hline Aerodynamic viscosity of coal seam, $\mu$ & $1.34 \times 10^{-5}$ & $\mathrm{~Pa} \cdot \mathrm{s}$ \\
\hline Unit weight of coal mass, $\gamma$ & 1.4 & $\mathrm{~g} / \mathrm{cm}^{3}$ \\
\hline Porosity, $n$ & $6.07 \%$ & - \\
\hline Coalbed methane density, $\rho$ & 0.714 & $\mathrm{~kg} / \mathrm{m}^{3}$ \\
\hline Adsorption constant of coalbed methane, $a$ & 24.15 & $\mathrm{~m}^{3} / \mathrm{kg}$ \\
\hline Coefficient of adsorption constant, $a$, affected by temperature & 0.003 & - \\
\hline Adsorption constant of coalbed methane, $b$ & 1.32 & $\mathrm{MPa}^{-1}$ \\
\hline Coefficient of adsorption constant, $b$, affected by temperature & 0.003 & - \\
\hline Water permeability coefficient, $k_{1}$ & $1.57 \times 10^{-3}$ & $\mathrm{mD}$ \\
\hline Fissure permeability coefficient, $k_{2}$ & $1.5 \times 10^{-2}$ & $\mathrm{mD}$ \\
\hline Heat conductivity coefficient of coal, $\lambda$ & 1.86 & $\mathrm{w} / \mathrm{m} \cdot \mathrm{k}$ \\
\hline Heat capacity coefficient of coalbed methane, $C_{g}$ & 2.16 & $\mathrm{KJ} /(\mathrm{Kg} \cdot \mathrm{K})$ \\
\hline Heat capacity coefficient of water, $C_{w}$ & 4.117 & $\mathrm{KJ} /(\mathrm{Kg} \cdot \mathrm{K})$ \\
\hline
\end{tabular}

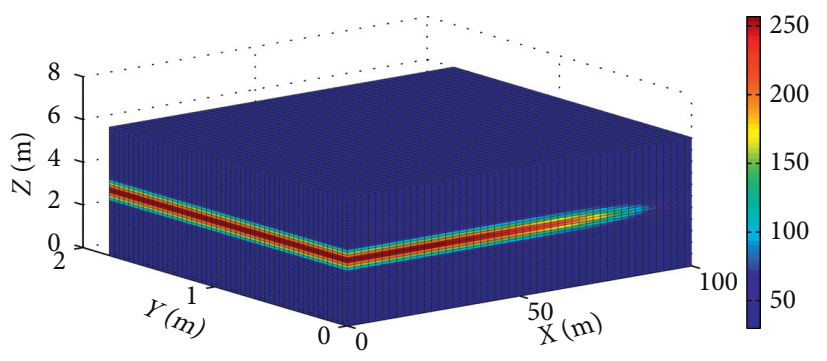

(a)

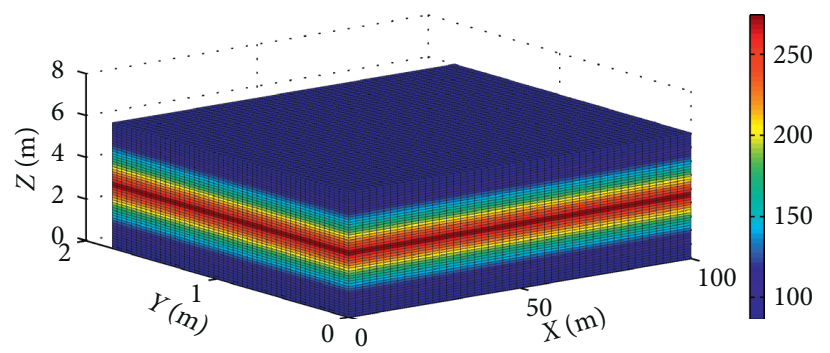

(c)

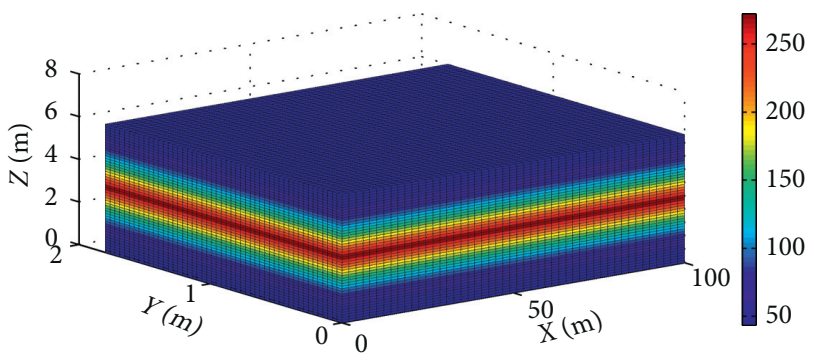

(b)

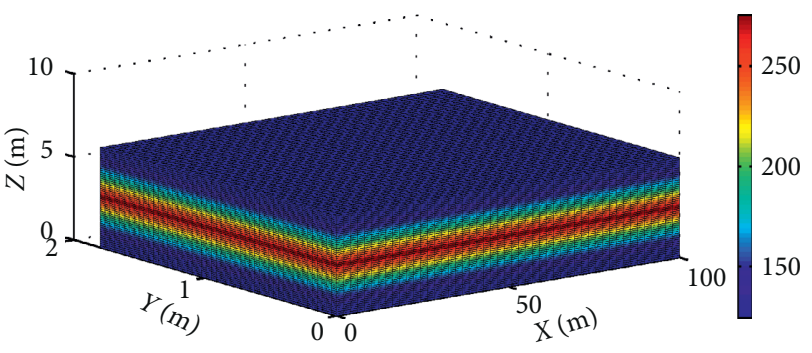

(d)

Figure 4: Simulation results of temperature: (a) 3 days, (b) 10 days, (c) 20 days, and (d) 30 days.

As seen from Figure 6, along with heat injection, the adsorbed gas near the fracture belt of coal seams underwent quick desorption, and the gas content in the area decreased rapidly. Bordered by the fissure, the gas content of the upper and lower parts of the coal seams weakened. On the 3rd day of heat injection, as shown in Figure 6(a), the absorbed gas content of the fissure zone clearly decreased, and the absorbed gas content of the area surrounding the heat injection holes decreased from $22.7 \mathrm{~m}^{3} / t$ to $2 \mathrm{~m}^{3} / t$; the absorbed gas content still reached $17.8 \mathrm{~m}^{3} / t$ at a distance of $3 \mathrm{~m}$ from the fissure zone. Most of the gas in other areas had not been desorbed at this point in time. Figures 6(b) and 6(c) are diagrams of absorbed gas content of the coal seams after heat injection for 10 days and 20 days, respectively, and the desorbed area gradually expanded along with heat injection of absorbed gas. In Figure 6(d), after heat injection and extraction for one month, the absorbed gas content of the coal mass in the simulated area clearly decreased, with the highest content only $2.5 \mathrm{~m}^{3} / t$.

Figure 7 is the distribution of adsorbed gas content near the vertical heat injection holes, and the absorbed gas content along with heat injection varied similarly as those in Figure 6.

4.2.3. Variation Trend of Total Gas Content. Figure 8 shows the variation of the total gas content of the coal seams. The gas content in one ton of coal in the primitive coalbeds in the model reached $23.8 \mathrm{~m}^{3}$; after heat injection for 3 days, the total gas content of the fissure zone decreased rapidly, with a minimum value of $1.2 \mathrm{~m}^{3} / \mathrm{t}_{\text {coal }}$. After 10 days, the total gas content of the coal seams continuously decreased, with the 


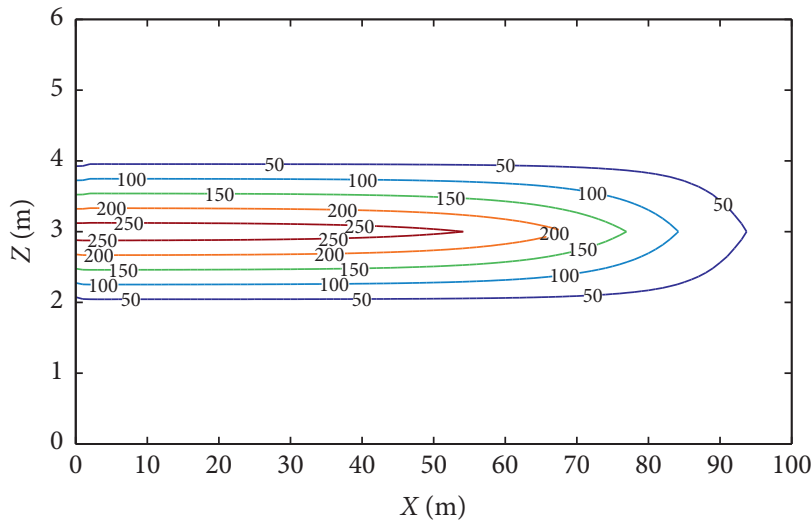

(a)

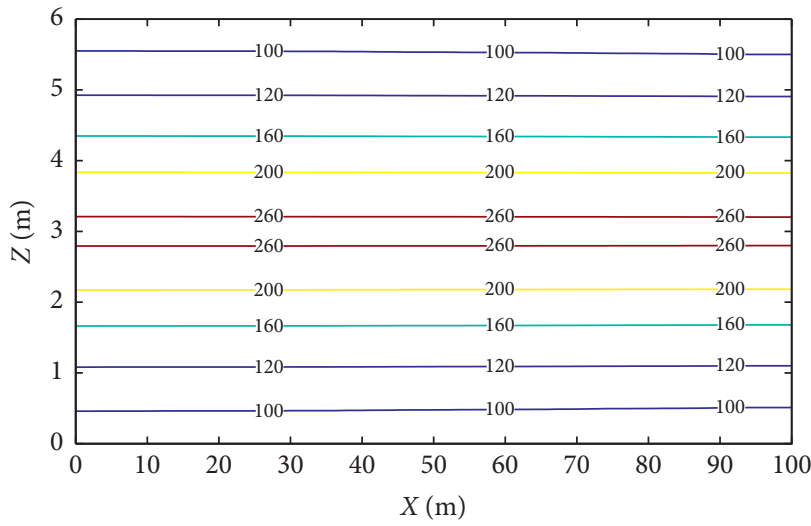

(c)

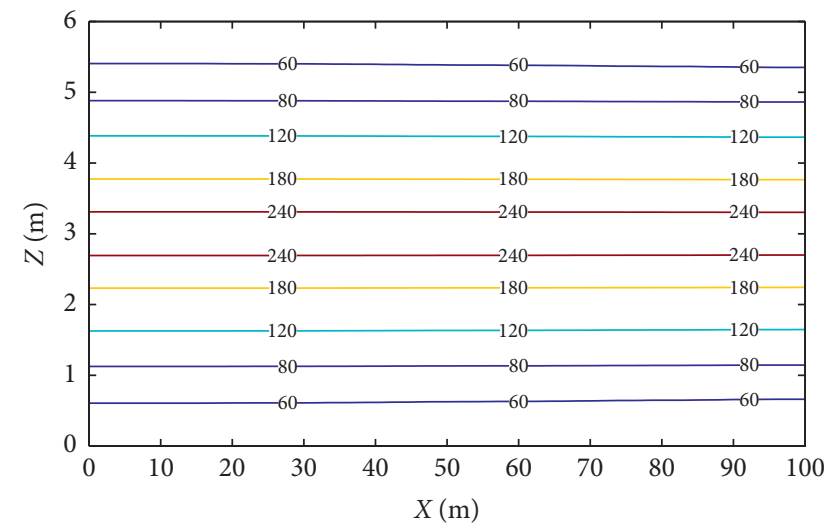

(b)

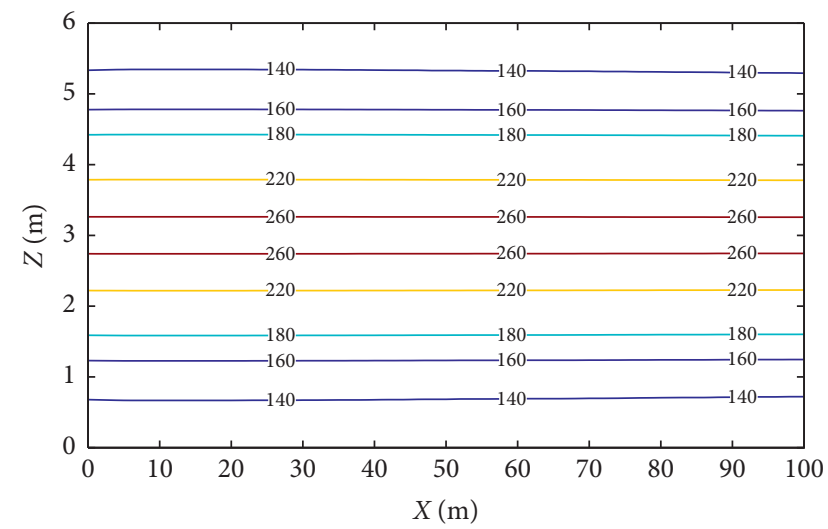

(d)

Figure 5: The temperature distribution in the section along the drill hole: (a) 3 days, (b) 10 days, (c) 20 days, and (d) 30 days.

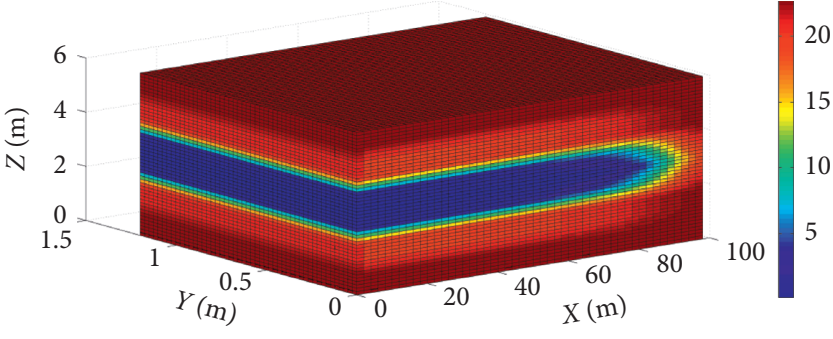

(a)

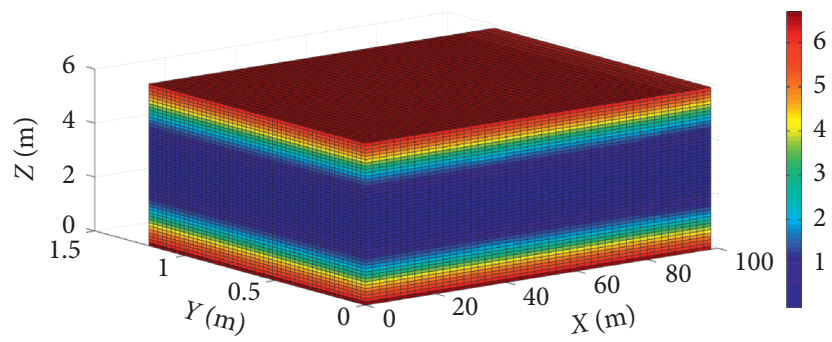

(c)

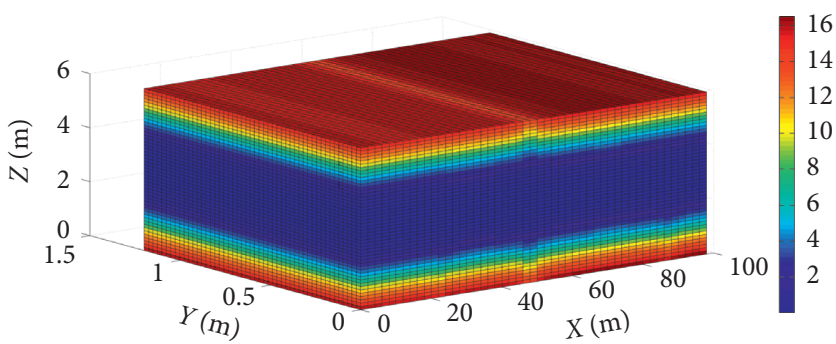

(b)

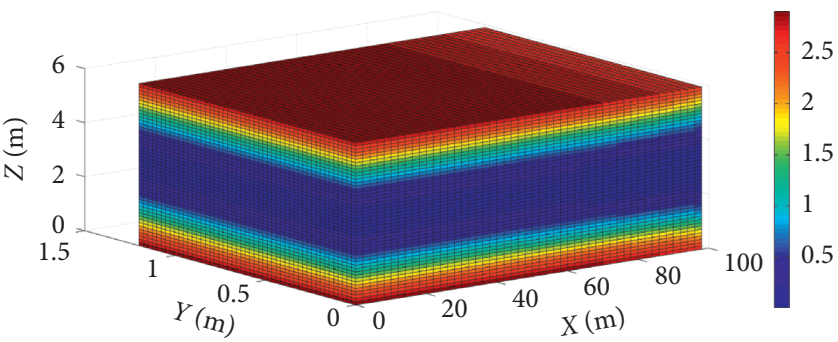

(d)

Figure 6: Simulation results of adsorbed gas content (unit: $\mathrm{m}^{3} / \mathrm{t}_{\text {coal }}$ ): (a) 3 days, (b) 10 days, (c) 20 days, and (d) 30 days. 


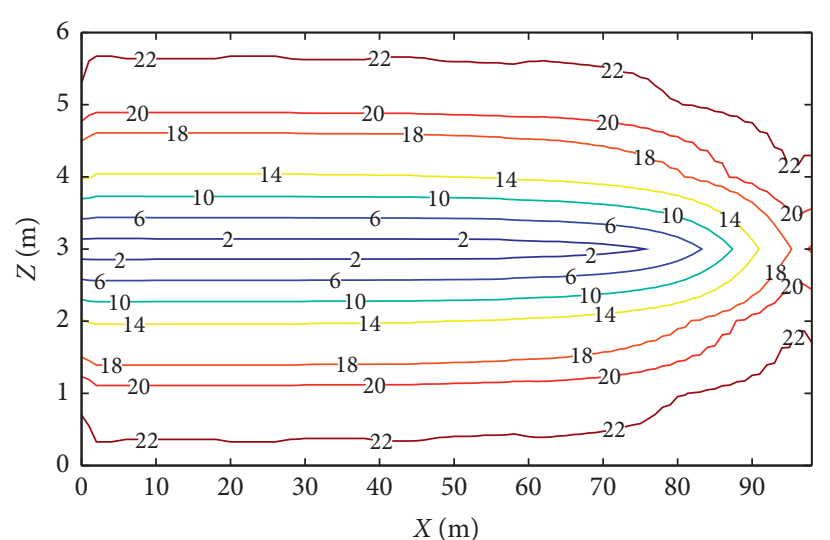

(a)

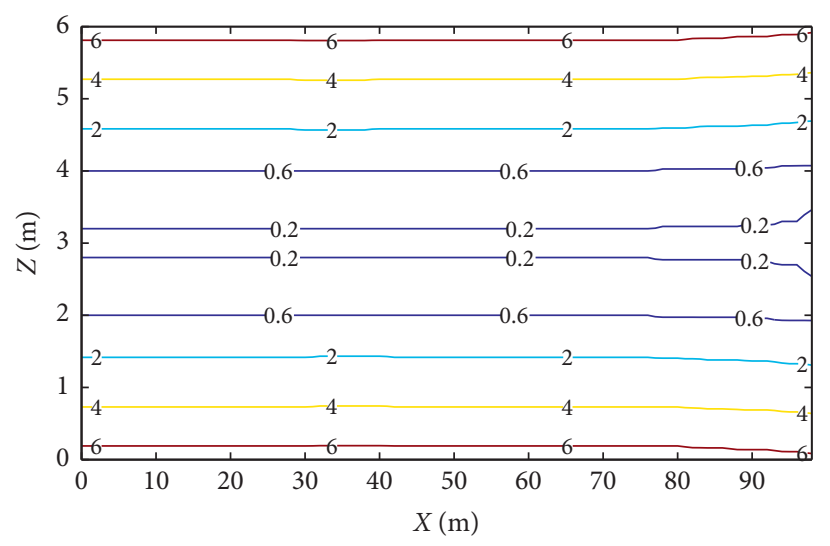

(c)

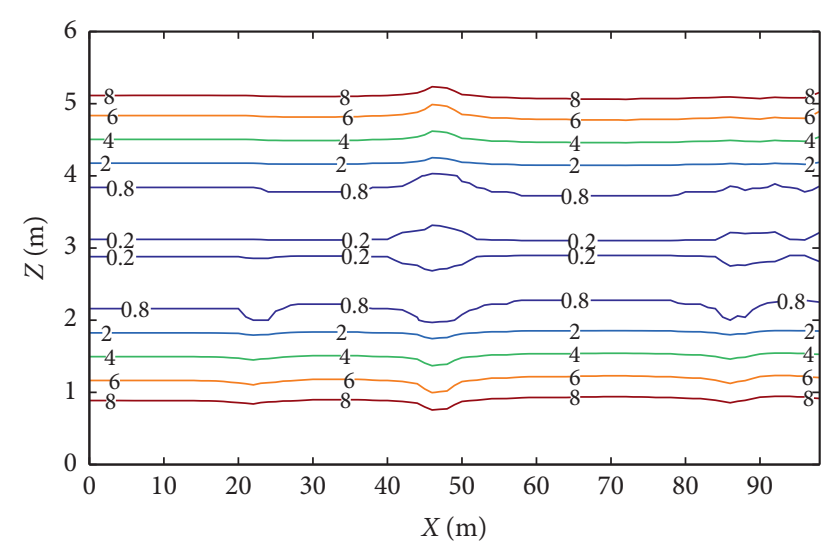

(b)

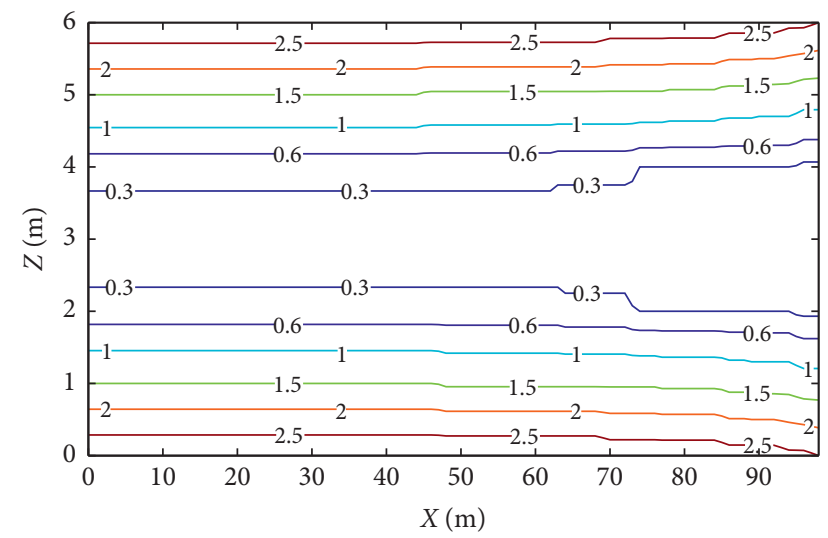

(d)

FIgURE 7: Simulation results of gas adsorption amount of section $y=0$ (unit: $\mathrm{m}^{3} / \mathrm{t}_{\text {coal }}$ ): (a) 3 days, (b) 10 days, (c) 20 days, and (d) 30 days.

total content at top beds down to $17.3 \mathrm{~m}^{3} / \mathrm{t}_{\text {coal }}$ and the minimum near the extraction holes. After 30 days, the maximum gas content of the coal seams reached $6.1 \mathrm{~m}^{3} / \mathrm{t}_{\text {coal }}$, with a minimum value of $1.2 \mathrm{~m}^{3} / \mathrm{t}_{\text {coal }}$. According to the area weighted average, the total gas content reached $3.5 \mathrm{~m}^{3} / \mathrm{t}_{\text {coal }}$, and the mining rate reached $85 \%$ within one month in the heat injection and extraction area of coalbed methane, which is an effect that has not been achieved by single extraction technology to date.

Figure 8 shows the contour map of total gas content, gas content decreased gradually along with heat injection from the top and bottom beds to the fissure zone, forming a pressure decrease funnel around the extraction hole, and the minimum value of the gas content in coal seams only reached $1.2 \mathrm{~m}^{3} / \mathrm{t}_{\mathrm{coal}}$.

4.2.4. Variation Trends of Coalbed Gas Pore Pressure with Heat Injection Process. As seen in Figure 10(a), after heat injection for 3 days, the pore pressure within $0 \sim 60^{\circ} \mathrm{m}$ of the fissure zone in the coal seams increased rapidly in the $x$ direction, the maximum gas pore pressure was $61 \mathrm{~atm}$, and the pore pressure gradually decreased to 39 atm from the fissure zone towards the top and bottom beds. In the vicinity of heat injection holes, the pore pressure of the coalbed gas was affected by extraction, which was lowered by $13.25 \mathrm{~atm}$ compared to the original pore pressure of the coalbed gas. From Figures 10(b)-10(d), the pore pressure of the coalbed gas had a greater uplift compared to the original pore pressure along with heat injection, and the pressure gradient between the extraction holes increased, conducive to extraction.

As seen from Figure 11, the pressure of the coalbed methane from the heat injection hole towards the drainage hole changed from high to low, allowing for the coalbed methane to flow towards the drainage hole. Figure 11(a) clearly shows that the pressure of coalbed methane was distributed along the fissure zone, in both directions vertically, which was the result of coalbed methane desorption caused by the temperature field variation. Due to drainage holes, a pressure decrease area formed near the center coordinate area of semicircular pressure decrease area (center coordinate $x, y=100^{\circ} \mathrm{m}$, $3^{\circ} \mathrm{m}$ ) that formed by extraction in Figure 11(a). Such a pressure gradient variation is reflected in Figures 11(b)11(d); namely, the pressure gradient caused by extraction of coalbed methane always existed. The left half of Figures 11(b)-11(d) contains high-pressure for up to 30 days, and the coalbed methane pressure increased to 40 atm to the utmost within $0 \sim 50 \mathrm{~m}$ in $x$ direction. This was because the desorbed coalbed methane was temporarily stored in the micropores and was not drained in a 


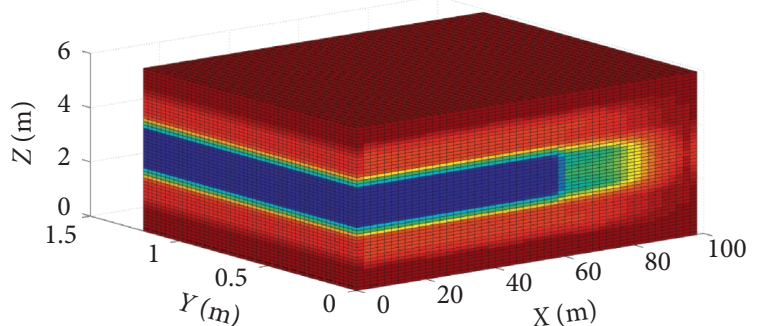

(a)

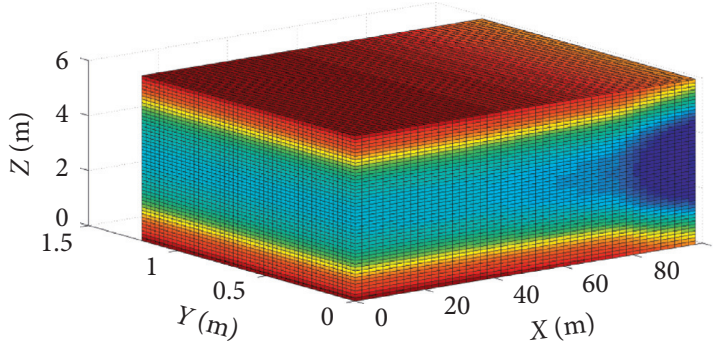

(c)
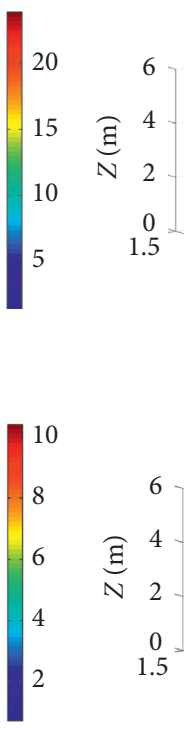

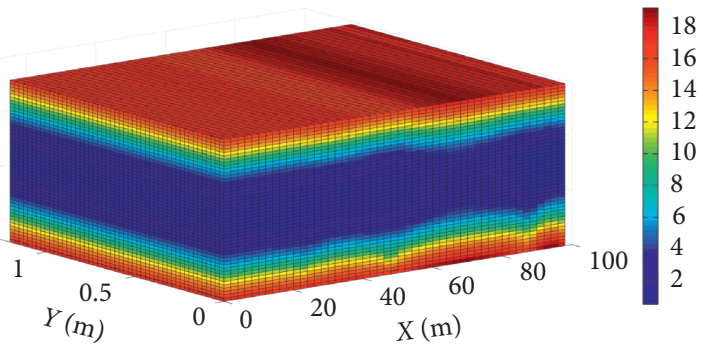

(b)

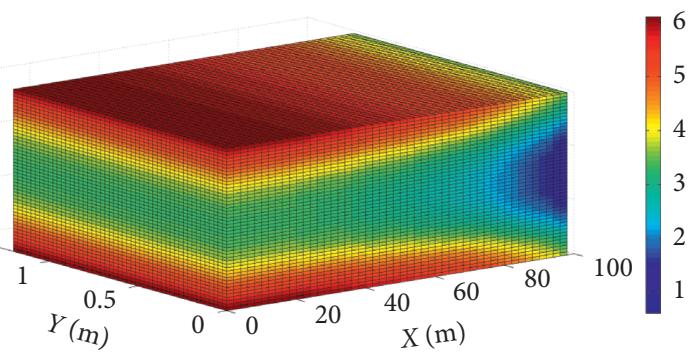

(d)

Figure 8: Variation of the total gas content of coal mass with heat injection and drainage time (unit: $\mathrm{m}^{3} / \mathrm{t}_{\text {coal }}$ ): (a) 3 days, (b) 10 days, (c) 20 days, and (d) 30 days.

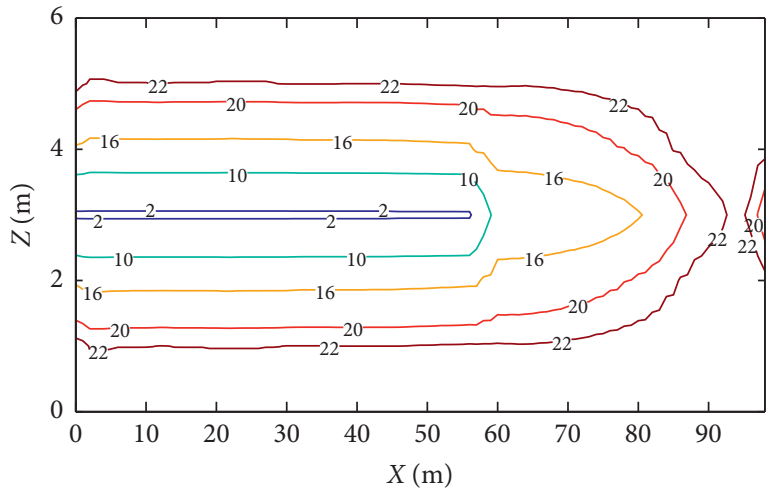

(a)

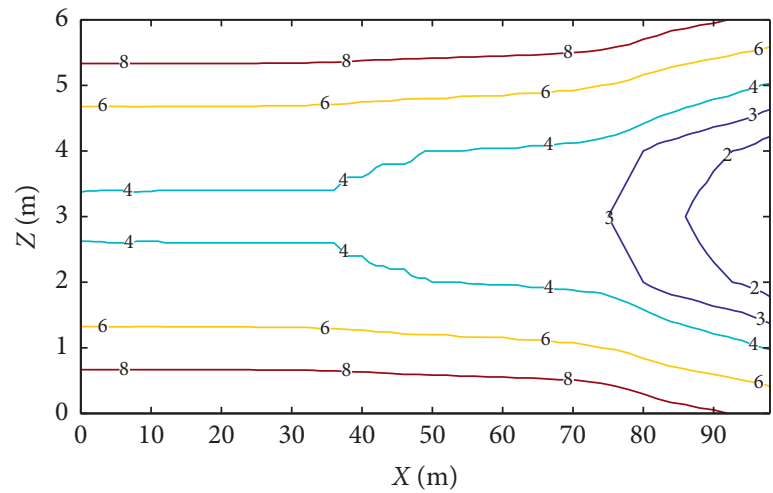

(c)

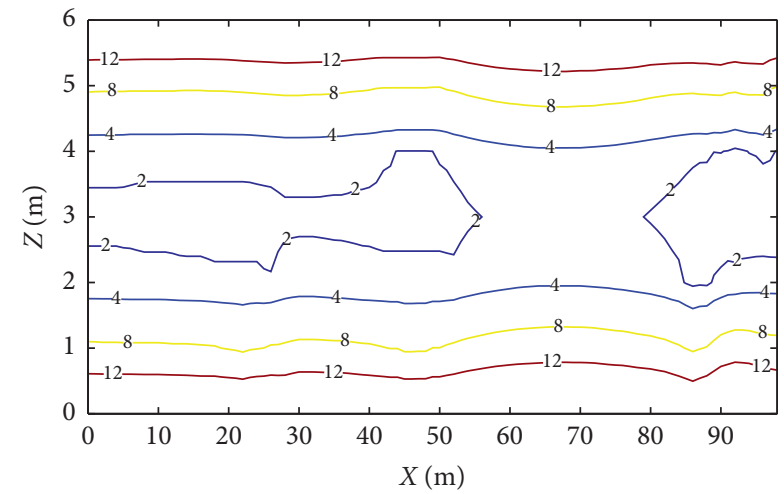

(b)

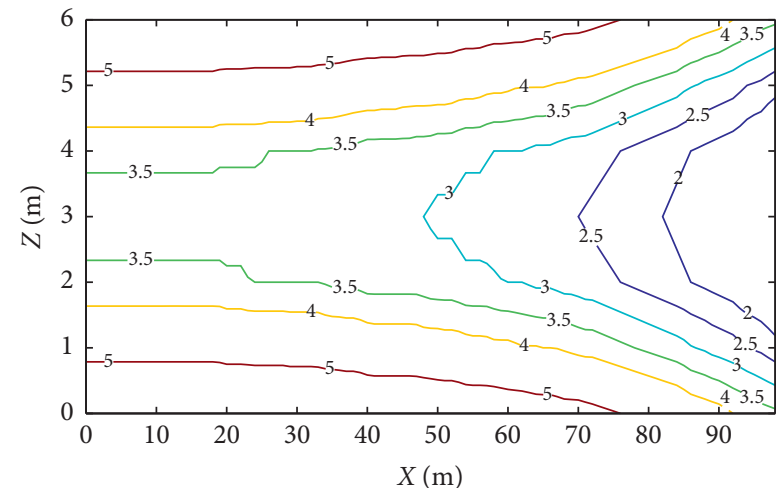

(d)

FIGURE 9: Variation trends of the total gas content of coal mass with heat injection and drainage time (unit: $\mathrm{m}^{3} / \mathrm{t}_{\text {coal }}$ ): (a) 3 days, (b) 10 days, (c) 20 days, and (d) 30 days. 


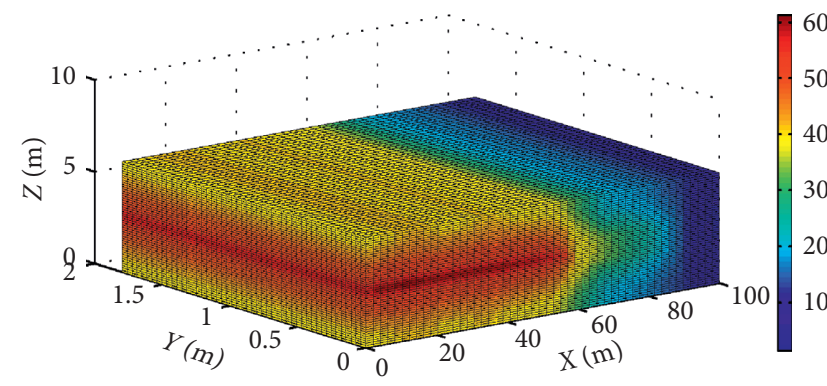

(a)

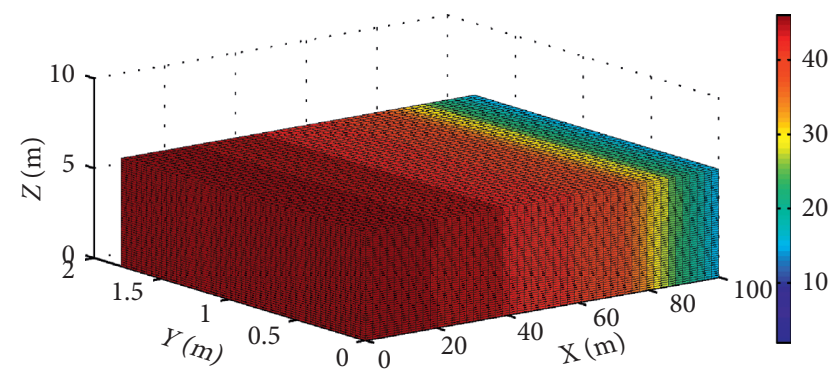

(c)

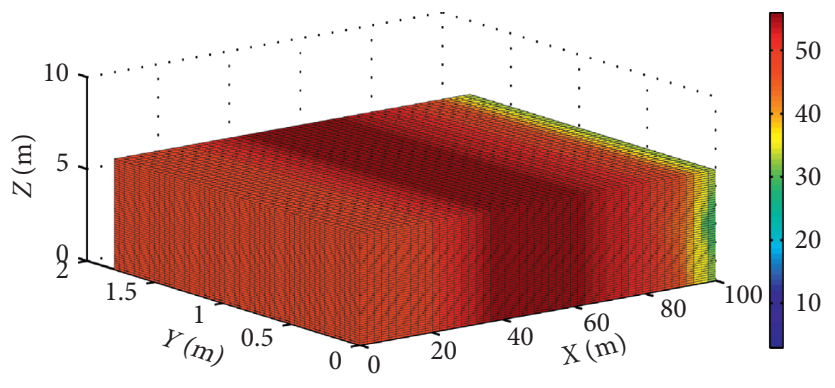

(b)

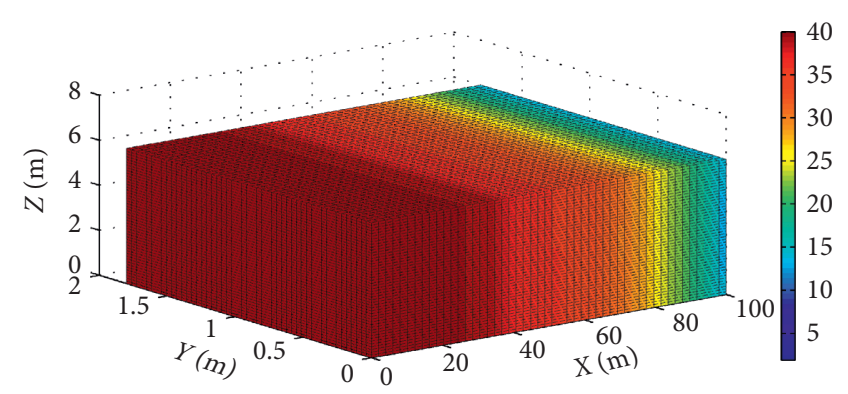

(d)

Figure 10: Simulation results of pore pressure: (a) 3 days, (b) 10 days, (c) 20 days, and (d) 30 days.

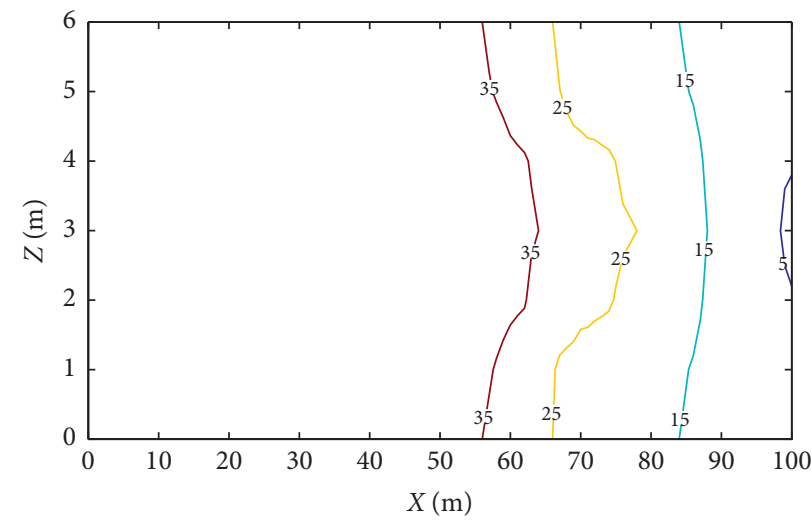

(a)

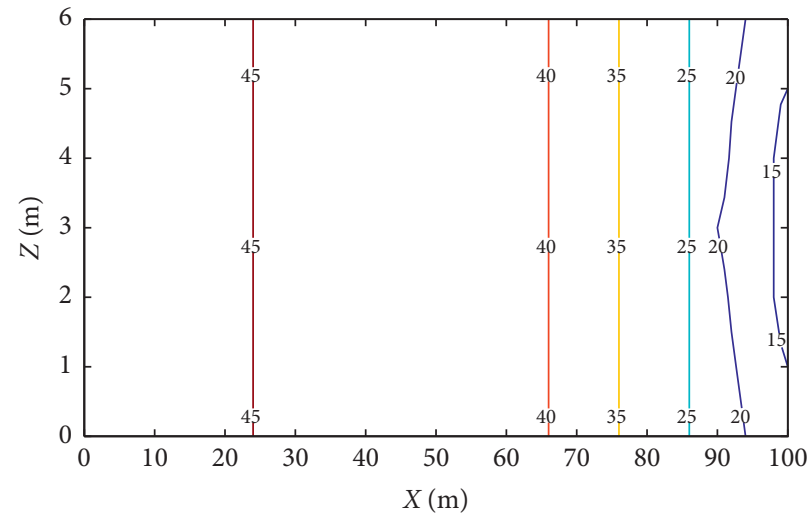

(c)

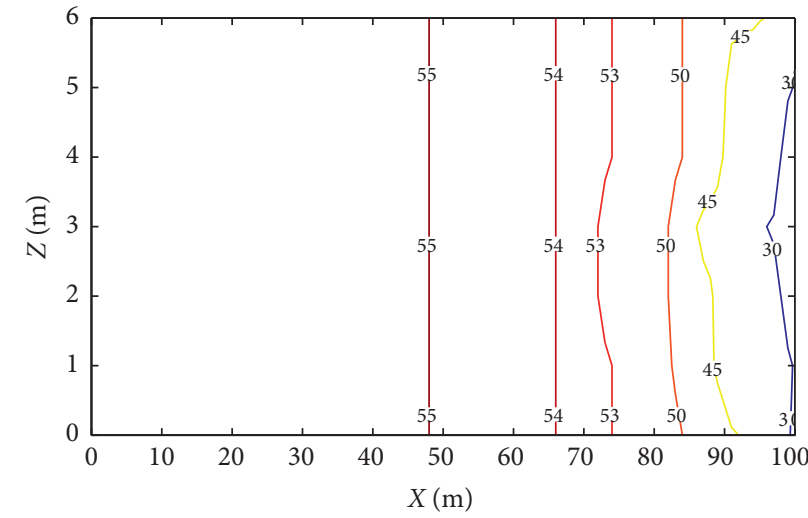

(b)

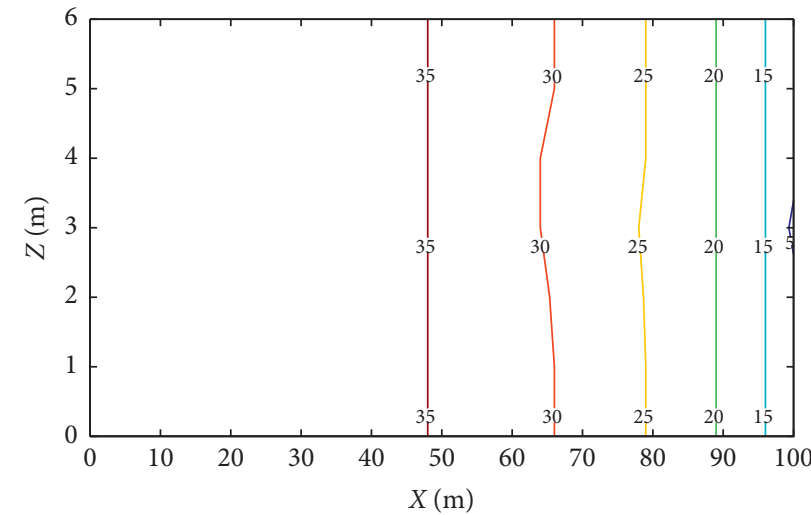

(d)

Figure 11: Sectional view of pore pressure: (a) 3 days, (b) 10 days, (c) 20 days, and (d) 30 days. 


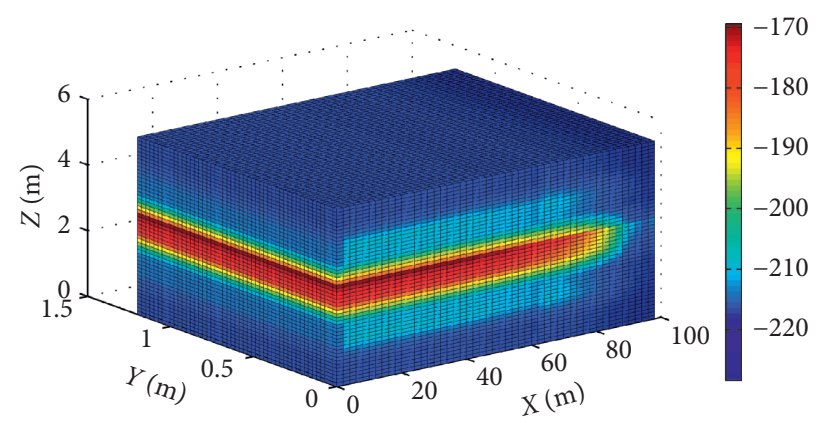

(a)

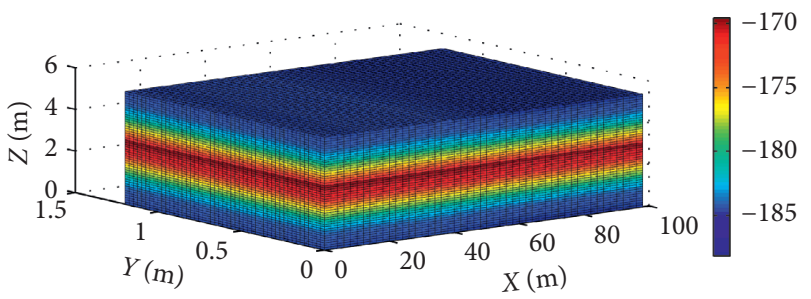

(c)

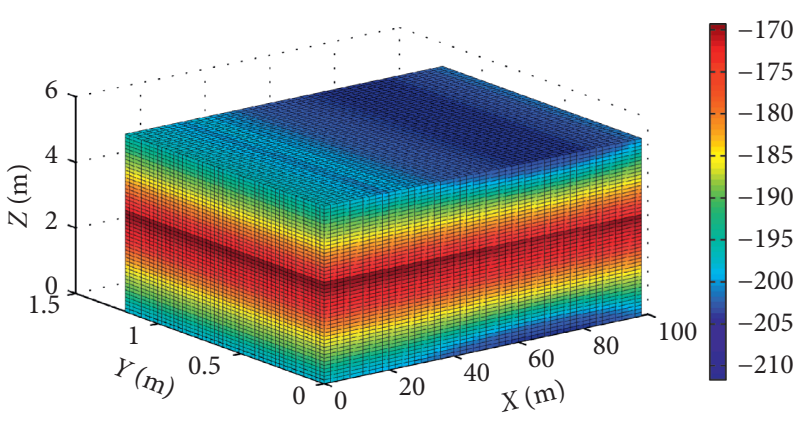

(b)

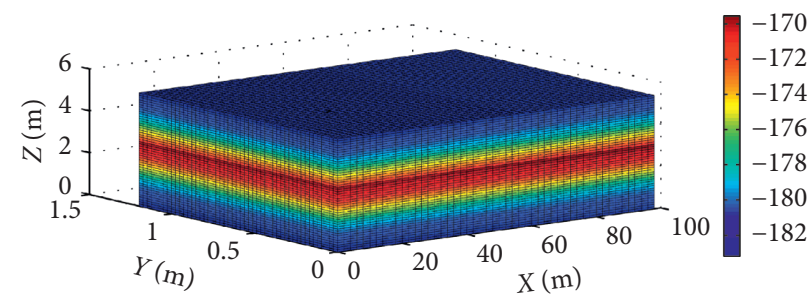

(d)

FIgURE 12: Simulation results of volume stress: (a) 3 days, (b) 10 days, (c) 20 days, and (d) 30 days.

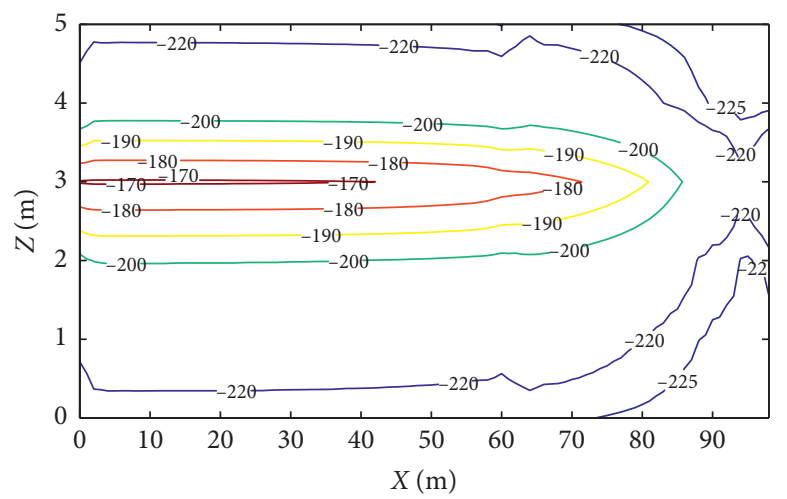

(a)

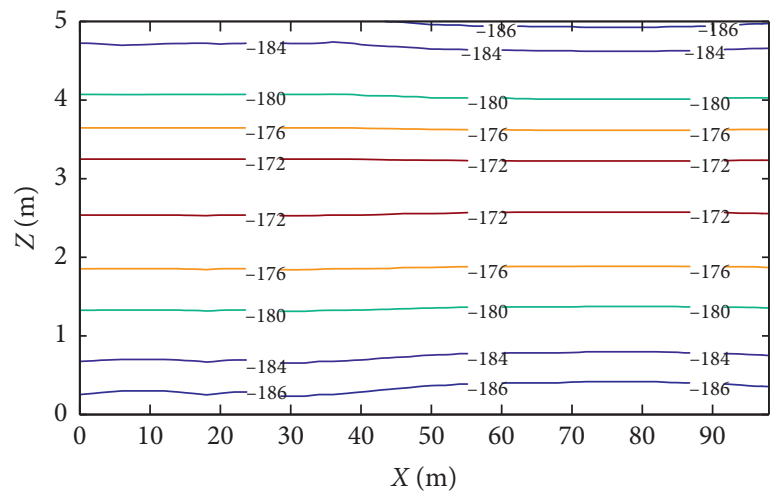

(c)

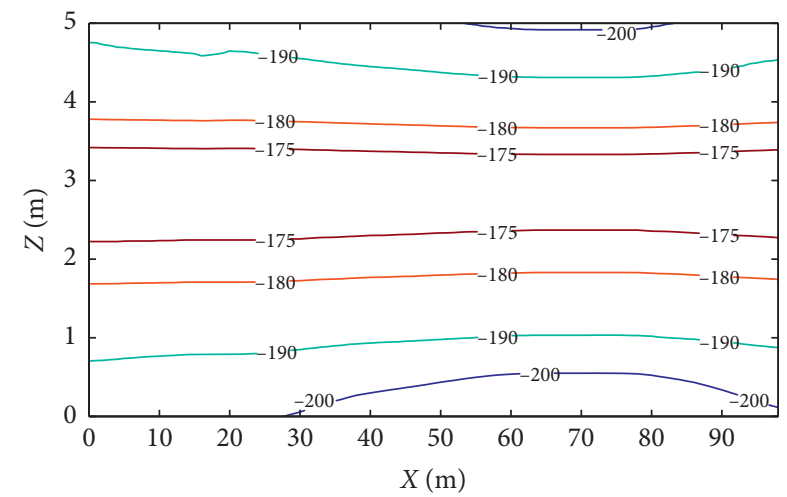

(b)

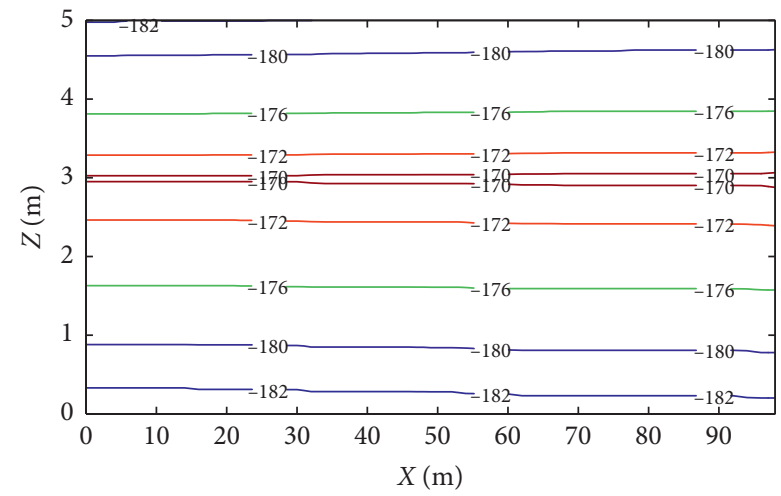

(d)

Figure 13: Sectional view of volume stress: (a) 3 days, (b) 10 days, (c) 20 days, and (d) 30 days. 
timely manner under high temperature, resulting in the rise in local pressure. Effects of gradual extraction moved from the drainage holes towards the heat injection well.

4.2.5. Variation Law of Volume Stress. As seen from Figure 12, along with heat injection, coalbed gas was gradually desorbed, and the local pore pressure of the desorbed coal matrix block increased. This in turn decreased the volume stress of coal mass under constant situation of total stress, and the temperature of the coal seams in the fissure zone more rapidly increased. Also, the absorbed gas underwent more desorption, so the volume stress from the fissure zone outwards vertically gradually decreased from $200 \mathrm{~kg} / \mathrm{cm}^{2}$ to $170 \mathrm{~kg} / \mathrm{cm}^{2}$.

As seen from Figure 13, the adsorbed gas content of coal mass gradually was desorbed, the pore pressure rose, and the volume stress decreased.

To sum up, the results of the simulation show extreme nonlinearity, which is closely related to the extreme nonlinearity of the mathematical model, and there is square term $p^{2}$ in the seepage equation of CBM. There is an exponent $e^{-\alpha T}$ affected by temperature in the content equation of CBM. The exponential item $e^{\gamma \mathrm{C}}$ in the volume expansion law is caused by CBM adsorption. The permeability of coalbed methane and water density are nonlinear, which makes the model appear extremely nonlinear. At the same time, the coupling effects of heat transfer, water seepage, CBM absorption, and coal-rock deformation are considered, so that the mathematical model of CBM migration coupled with deformation, seepage, and heat transfer is more comprehensive and complete. The nonlinearity of the calculation results is the reflection of the above reasons.

\section{Conclusions}

Through in-depth analysis on the mechanisms of coalbed methane extraction using heat injection in coal seams and industrial schemes, this paper analyzed the complex coupling process of temperature field, gas-water seepage field, and coal mass deformation field for desorption and seepage of coalbed methane using heat injection. The following can be concluded:

(1) A solid-fluid-heat coupling mathematical model of coalbed methane extraction using heat injection was established, with distinctive characteristics that the right end of the coalbed methane equation contained the pore variation action term $\partial n / \partial t$, the action term $\partial S_{g} / \partial t$ of gas-liquid relative saturation, the action term $\partial p_{g} / \partial t$ of free gas pore pressure variation, temperature variation action term $\partial T / \partial t$, and the action term of coalbed methane migration cause by temperature gradient under high temperature. These are a key development in the theory of coalbed methane transport.

(2) Under water pressure, the temperature of coal seams increased rapidly along the fissure zone. After 30 days, the temperature reached $260^{\circ} \mathrm{C}$ within $2^{\circ} \mathrm{m}$ of the fissure zone outwards vertically. The minimum

temperature of coal seams on both sides of the fissure zone reached $140^{\circ} \mathrm{C}$.

(3) The pore pressure of the coal seams gradually increased with the increase of temperature. After heat injection for 10 days, the pore pressure of the coal seams in the heat injection area increased to $5.5 \mathrm{MPa}$, and after 30 days, the pressure remained constant at 3.5 Mpa. Such a high fracturing gradient promoted the rapid flow and drainage of gas. The coalbed methane mainly took seepage in the direction parallel to the fissures, forming a pressure decrease round funnel near the drainage holes. This funnel area gradually expanded along with heat injection and extraction.

(4) Under high temperature, the coalbed gas was desorbed quickly, the absorbed gas content formed an oval funnel from the heat injection hole towards the extraction hole, centered by the fractured fissure and outwards vertically towards the coalbed upper and lower boundaries. Along with heat injection and extraction, the absorbed gas content rapidly decreased. On the 30th day, the absorbed gas content of the entire heat injection area decreased to $1.5 \mathrm{~m}^{3} / t$, only $7 \%$ of the original content.

\section{Symbols}

Physical parameters:

$q_{x f}$ :

$q_{x f}:$

$q_{y l}$ :

$n$ :

$\rho:$

$\rho_{g}:$

$\rho:$

$\rho_{s}:$

$\rho_{0}$ :

$P_{g}$ :

$p_{w}$ :

M:

$R:$

$t:$

$T_{r}$ :

$T_{w}$ :

T:

a:

$b$ :

$a_{0}$ :

$b_{0}$ :
Physical meaning (dimension of physical parameters)

Content of coalbed methane adsorbed in the coal body $\left(\left[\mathrm{ML}^{-3}\right]\right)$

Content of coalbed methane adsorbed in the coal body $\left(\left[\mathrm{ML}^{-3}\right]\right)$

Content of free coalbed methane in the coal body $\left(\left[\mathrm{ML}^{-3}\right]\right)$

Porosity (1)

Density of water $\left(\left[\mathrm{ML}^{-3}\right]\right)$

Density of gas $\left(\left[\mathrm{ML}^{-3}\right]\right)$

Density of gas-liquid two-phase mixed fluid $\left(\left[\mathrm{ML}^{-3}\right]\right)$

Density of the rock matrix $\left(\left[\mathrm{ML}^{-3}\right]\right)$

Gas density at normal temperature and one atmosphere $\left(\left[\mathrm{ML}^{-3}\right]\right)$

Pore gas pressure $\left(\left[\mathrm{ML}^{-1} \mathrm{~T}^{-2}\right]\right)$

Pore water pressure $\left(\left[\mathrm{ML}^{-1} \mathrm{~T}^{-2}\right]\right)$

Molar mass $\left(\left[\mathrm{Mn}^{-1}\right]\right)$

Gas constant $\left(\left[\mathrm{ML}^{2} \mathrm{~T}^{-2} \mathrm{n}^{-1} \theta^{-1}\right]\right)$

Time ([T])

Temperature of the rock matrix $([\theta])$

Water temperature $([\theta])$

Absolute temperature $([\theta])$

Langmuir adsorption constant $\left(\left[\mathrm{ML}^{-3}\right]\right)$

Langmuir adsorption constant

(dimensionless)

Langmuir adsorption constant of coal at normal temperature $\left(\left[\mathrm{ML}^{-3}\right]\right)$

Langmuir adsorption constant of coal at normal temperature (dimensionless) 


\begin{tabular}{|c|c|}
\hline$\alpha_{T}, \beta_{T}:$ & $\begin{array}{l}\text { Exponential decay coefficient of adsorption } \\
\text { constant with respect to temperature } \\
\text { (dimensionless) }\end{array}$ \\
\hline$C:$ & $\begin{array}{l}\text { Total content of coalbed methane in the } \\
\text { coal body }\left(\left[\mathrm{ML}^{-3}\right]\right)\end{array}$ \\
\hline E: & Volumetric strain $(1)$ \\
\hline$\gamma:$ & $\begin{array}{l}\text { Deformation coefficient of coal caused by } \\
\text { gas adsorption (dimensionless) }\end{array}$ \\
\hline$q_{g i}:$ & Gas specific flux $\left(\left[\mathrm{LT}^{-1}\right]\right)$ \\
\hline$q_{w i}$ : & Water specific flux $\left(\left[\mathrm{LT}^{-1}\right]\right)$ \\
\hline$\Theta:$ & Volume stress $\left(\left[\mathrm{ML}^{-1} \mathrm{~T}^{-2}\right]\right)$ \\
\hline$\alpha:$ & Effective stress coefficient (dimensionless) \\
\hline$\alpha_{1}, \alpha_{2}, \alpha_{3}, \alpha_{4}$ & $\begin{array}{l}\text { The experimental constant of the effective } \\
\text { stress coefficient obeying the bilinear law } \\
\text { (dimensionless) }\end{array}$ \\
\hline$S_{g}, S_{w}:$ & $\begin{array}{l}\text { Relative saturation of gas and water in coal } \\
\text { pore/fissures (1) }\end{array}$ \\
\hline$k_{i}:$ & $\begin{array}{l}\text { Permeability of fluid in a certain direction } \\
\left(\left[\mathrm{L}^{2}\right]\right)\end{array}$ \\
\hline$\mu_{g}:$ & $\begin{array}{l}\text { Dynamic viscosity coefficient of coalbed } \\
\text { methane }\left(\left[\mathrm{ML}^{-1} \mathrm{~T}^{-1}\right]\right)\end{array}$ \\
\hline$C_{s}:$ & Specific heat capacity of coal $\left(\left[\mathrm{L}^{2} \mathrm{~T}^{-2} \theta^{-1}\right]\right)$ \\
\hline$C_{p}:$ & $\begin{array}{l}\text { Specific heat capacity of gas-liquid two- } \\
\text { phase mixed fluid }\left(\left[\mathrm{L}^{2} \mathrm{~T}^{-2} \theta^{-1}\right]\right)\end{array}$ \\
\hline$\lambda_{\mathrm{z}}:$ & $\begin{array}{l}\text { Thermal conductivity of gas-liquid two- } \\
\left.\left.\text { phase mixed fluid ([LMT }{ }^{-3} \theta^{-1}\right]\right)\end{array}$ \\
\hline$\lambda_{\mathrm{s}}:$ & $\begin{array}{l}\text { Thermal conductivity of the rock matrix } \\
\left(\left[\mathrm{LMT}^{-3} \theta^{-1}\right]\right)\end{array}$ \\
\hline$\lambda_{\mathrm{w}}:$ & $\begin{array}{l}\text { Thermal conductivity of water } \\
\left(\left[\mathrm{LMT}^{-3} \theta^{-1}\right]\right)\end{array}$ \\
\hline$\lambda_{\mathrm{g}}:$ & $\begin{array}{l}\text { Thermal conductivity of coalbed methane } \\
\left(\left[\mathrm{LMT}^{-3} \theta^{-1}\right]\right)\end{array}$ \\
\hline$v:$ & Poisson's ratio $(1)$ \\
\hline$\omega_{C}:$ & $\begin{array}{l}\text { Coefficient of volume expansion stress of } \\
\text { the coal matrix caused by adsorbing coalbed } \\
\text { methane (dimensionless) }\end{array}$ \\
\hline$\beta s:$ & $\begin{array}{l}\text { Coefficient of volume expansion stress of } \\
\text { the coal matrix caused by thermal stress } \\
\left(\left[\mathrm{ML}^{-1} \mathrm{~T}^{-2}\right]\right)\end{array}$ \\
\hline$\lambda:$ & One of the lame constants $\left(\left[\mathrm{ML}^{-1} \mathrm{~T}^{-2}\right]\right)$ \\
\hline$\mu:$ & One of the lame constants $\left(\left[\mathrm{ML}^{-1} \mathrm{~T}^{-2}\right]\right)$ \\
\hline$U_{\mathrm{i}}:$ & Solid displacement component $([\mathrm{L}])$ \\
\hline$F_{\mathrm{i}}:$ & $\begin{array}{l}\text { Applied to rock mass body force } \\
\text { component }\left(\left[\mathrm{ML}^{-1} \mathrm{~T}^{-2}\right]\right)\end{array}$ \\
\hline$E:$ & Elastic modulus $\left(\left[\mathrm{ML}^{-1} \mathrm{~T}^{-2}\right]\right)$ \\
\hline$Q_{0}:$ & Source sink term of heat $\left(\left[\mathrm{ML}^{-1} \mathrm{~T}^{-3}\right]\right)$ \\
\hline$\delta_{\mathrm{ij}}:$ & Kronecker symbol (dimensionless) \\
\hline$\delta_{\mathrm{w}}$ & $\begin{array}{l}\text { Related to the density of water, not exceed } \\
6 \% \text { of } 1 / \rho_{\mathrm{w}} \text { (dimensionless) }\end{array}$ \\
\hline$c_{p r}:$ & Specific heat of the coal matrix $\left(\left[\mathrm{L}^{2} \mathrm{~T}^{-2} \theta^{-1}\right]\right)$ \\
\hline$c_{p w}:$ & Specific heat of water $\left(\left[\mathrm{L}^{2} \mathrm{~T}^{-2} \theta^{-1}\right]\right)$ \\
\hline$u, v, w:$ & $\begin{array}{l}\text { The velocity of flow in three directions } \\
\left(\left[\mathrm{LT}^{-1}\right]\right) \text {. }\end{array}$ \\
\hline
\end{tabular}

\section{Data Availability}

All the data used to support this study are present within the article as figures and tables.

\section{Conflicts of Interest}

The authors declare that there are no conflicts of interest regarding the publication of this paper.

\section{Acknowledgments}

This paper was supported by the Key Research and Development (R\&D) Projects of Shanxi Province (Grant no. 201603D121031), Applied Basic Research Programs of Shanxi Province (201801D121278; 201801D221357; 201901D211294; 201901D211300), and Natural Science Funds for Young Scholar (Grant no. 51904195).

\section{References}

[1] Y. Zhao, Z. Jin, and J. Sun, "Mathematical model for coupled solid deformation and methane flow in coal seams," Applied Mathematical Modelling, vol. 18, no. 6, pp. 328-333, 1994.

[2] Y. Zhao, Y. Hu, B. Zhao, and D. Yang, "Nonlinear coupled mathematical model for solid deformation and gas seepage in fractured media," Transport in Porous Media, vol. 55, no. 2, pp. 119-136, 2004

[3] J. Liu, Z. Chen, D. Elsworth, H. Qu, and D. Chen, "Interactions of multiple processes during CBM extraction: a critical review," International Journal of Coal Geology, vol. 87, no. 3-4, pp. 175-189, 2011.

[4] Z. Wang, G. Wang, V. Rudolph, d. C. J. C. Diniz, P. M. Huang, and L. Xin, "Simulation of $\mathrm{CO}_{2}$-geosequestration enhanced coal bed methane recovery with a deformation-flow coupled model," Procedia Earth and Planetary Science, vol. 1, no. 1, pp. 81-89, 2009.

[5] F. Gu and R. Chalaturnyk, "Permeability and porosity models considering anisotropy and discontinuity of coalbeds and application in coupled simulation," Journal of Petroleum Science and Engineering, vol. 74, no. 3-4, pp. 113-131, 2010.

[6] H. Zhang, J. Liu, and D. Elsworth, "How sorption-induced matrix deformation affects gas flow in coal seams: a new FE model," International Journal of Rock Mechanics and Mining Sciences, vol. 45, no. 8, pp. 1226-1236, 2008.

[7] Z. Chen, J. Liu, D. Elsworth, L. D. Connell, and Z. Pan, "Impact of $\mathrm{CO}_{2}$ injection and differential deformation on $\mathrm{CO}_{2}$ injectivity under in-situ stress conditions," International Journal of Coal Geology, vol. 81, no. 2, pp. 97-108, 2010.

[8] Y. Wu, J. Liu, Z. Chen, D. Elsworth, and D. Pone, "A dual poroelastic model for CO2-enhanced coalbed methane recovery," International Journal of Coal Geology, vol. 86, no. 2-3, pp. 177-189, 2011.

[9] Y. Wu, J. Liu, D. Elsworth, X. Miao, and X. Mao, "Development of anisotropic permeability during coalbed methane production," Journal of Natural Gas Science and Engineering, vol. 2, no. 4, pp. 197-210, 2010.

[10] G. Liu and A. V. Smirnov, "Modeling of carbon sequestration in coal-beds: a variable saturated simulation," Energy Conversion and Management, vol. 49, no. 10, pp. 2849-2858, 2008.

[11] G. Liu and A. V. Smirnov, "Carbon sequestration in coal-beds with structural deformation effects," Energy Conversion and Management, vol. 50, no. 6, pp. 1586-1594, 2009.

[12] Z. Wei and D. Zhang, "Coupled fluid-flow and geomechanics for triple-porosity/dual-permeability modeling of coalbed methane recovery," International Journal of Rock Mechanics and Mining Sciences, vol. 47, no. 8, pp. 1242-1253, 2010. 
[13] B. Liang, J. Liu, H. Fan, M. Zhang, B. Liang, and J. Liu, "The mathematical model and numerical solution of gas flow under unequal temperature," Chinese Journal of Mathematics, vol. 19, no. 1, pp. 1-5, 2000, in Chinese.

[14] K. Sun, Y. Pan, and B. Liang, "Numerical simulation of deep coal-bed-methane multi-well exploitation under fluid-solid coupling," Chinese Journal of Rock Mechanics and Engineering, vol. 26, no. 5, pp. 994-1001, 2007, in Chinese.

[15] T. Xia, F. Zhou, F. Gao, J. Kang, J. Liu, and J. Wang, "Simulation of coal self-heating processes in underground methane-rich coal seams," International Journal of Coal Geology, vol. 142, pp. 1-12, 2015.

[16] W. C. Zhu, C. H. Wei, J. Liu, H. Y. Qu, and D. Elsworth, "A model of coal-gas interaction under variable temperatures," International Journal of Coal Geology, vol. 86, no. 2-3, pp. 213-221, 2011.

[17] S. Li, C. Fan, J. Han, M. Luo, Z. Yang, and H. Bi, “A fully coupled thermal-hydraulic-mechanical model with two-phase flow for coalbed methane extraction," Journal of Natural Gas Science and Engineering, vol. 33, pp. 324-336, 2016.

[18] Z. J. Chen, Z. Pan, L. D. Connell, and D. Elsworth, "Influence of the effective stress coefficient and sorption-induced strain on the evolution of coal permeability: model development and analysis," International Journal of Greenhouse Gas Control, vol. 8, pp. 101-110, 2012.

[19] Y. Zhou, Z. Li, Y. Yang et al., "Improved porosity and permeability models with coal matrix block deformation effect," Rock Mechanics and Rock Engineering, vol. 49, no. 9, pp. 3687-3697, 2016.

[20] G. Sang, D. Elsworth, S. Liu, and S. Harpalani, "Characterization of swelling modulus and effective stress coefficient accommodating sorption-induced swelling in coal," Energy \& Fuels, vol. 31, no. 9, pp. 8843-8851, 2017.

[21] L. Si, Z. Li, D. Xue, J. Zhou, Y. Yang, and Y. Zhou, "Modeling and application of gas pressure measurement in water-saturated coal seam based on methane solubility," Transport in Porous Media, vol. 119, no. 1, pp. 163-179, 2017.

[22] Z. Feng, Y. Zhao, Z. Lv, D. Yang, J. Liu, and D. Zhao, Method of Extraction of Coalbed Methane on Heating CN, in Chinese, 2009.

[23] Y. Zhao, Multi-filed Coupling Effect and Engineering Response of Porous Media, Beijing: Science Press, Beijing, China, 2010, in Chinese.

[24] D. Zhao, Y. S. Zhao, Z. C. Feng, Z. X. Liu, and T. Liu, "Experiments of methane adsorption on raw coal at 30-270 C," Energy Sources, Part A: Recovery, Utilization, and Environmental Effects, vol. 34, no. 4, pp. 324-331, 2011.

[25] Y. Zhao, Y. Hu, D. Yang, and J. Wei, "The experimental study on the gas seepage law of rock related in adsorption under 3-D stress," Chinese Journal of Rock Mechanical Engineering, vol. 18, no. 6, pp. 653-655, 1999, in Chinese.

[26] Y. Zhao, Y. Hu, J. Wei, and D. Yang, "The experimental approach to effective stress law of coal mass by effect of methane," Transport in Porous Media, vol. 53, no. 3, pp. 235-244, 2003.

[27] T. Meng, Y. Yue, J. Ma et al., "Use of DC voltage fluctuation method to investigate real-time mode I and mode II subcritical crack growth behavior in gypsum rock," Engineering Fracture Mechanics, vol. 234, p. 107104, 2020.

[28] M. Tao, X. Jl, L. Xm, M. Jw, and Y. Yang, "Experimental study on the evolutional trend of pore structures and fractal dimension of low-rank clay rich coal subjected to a coupled thermo-hydro-mechanical-chemical environment," Energy, vol. 203, p. 117838, 2020. 